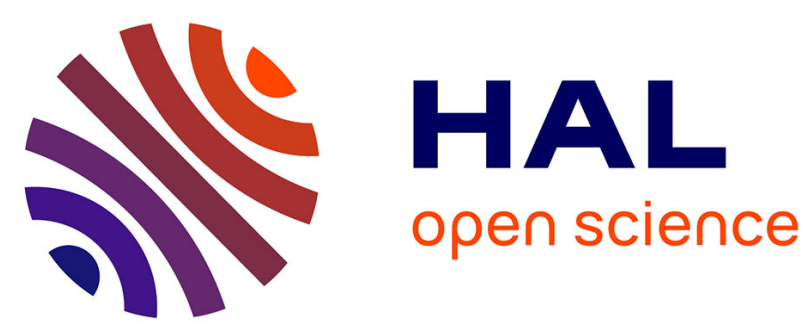

\title{
Argonaute-2 is associated to brown adipose tissue activation
}

Estelle Roger, Olivier Dumortier, Didier Pisani, Nadine Gautier, Emmanuel van Obberghen, Charlotte Hinault

\section{- To cite this version:}

Estelle Roger, Olivier Dumortier, Didier Pisani, Nadine Gautier, Emmanuel van Obberghen, et al.. Argonaute-2 is associated to brown adipose tissue activation. Biochimica et Biophysica Acta - Molecular Basis of Disease, 2019, 1865 (9), pp.2393-2402. 10.1016/j.bbadis.2019.05.018 . hal-02323514

\section{HAL Id: hal-02323514 https://hal.science/hal-02323514}

Submitted on 1 Dec 2020

HAL is a multi-disciplinary open access archive for the deposit and dissemination of scientific research documents, whether they are published or not. The documents may come from teaching and research institutions in France or abroad, or from public or private research centers.
L'archive ouverte pluridisciplinaire HAL, est destinée au dépôt et à la diffusion de documents scientifiques de niveau recherche, publiés ou non, émanant des établissements d'enseignement et de recherche français ou étrangers, des laboratoires publics ou privés. 


\title{
Argonaute-2 is associated to brown adipose tissue activation
}

\author{
Estelle Roger ${ }^{4,5}$, Olivier Dumortier ${ }^{4}$, Didier F Pisani ${ }^{6}$, Nadine Gautier ${ }^{4,6}$, \\ Emmanuel Van Obberghen ${ }^{1,3,7^{*}}$ and Charlotte Hinault ${ }^{1,2,7^{*}}$
}

${ }^{1}$ Université Côte d'Azur, CHU, Inserm, CNRS, IRCAN, France.

${ }^{2}$ Université Côte d'Azur, CHU, Inserm, C3M, France.

${ }^{3}$ Université Côte d'Azur, CNRS, LP2M, France.

${ }^{4}$ Université Côte d'Azur, Inserm, CNRS, IRCAN, France.

${ }^{5}$ Université Côte d'Azur, Inserm, C3M, France.

${ }^{6}$ Université Côte d'Azur, CNRS, Inserm, iBV, France.

${ }^{7}$ Co-senior authors.

\section{* Correspondence:}

hinault@unice.fr

vanobbeg@unice.fr

C3M, Team 5

151 Route de St Antoine de Ginestière

LP2M, Medical Faculty

06204 Nice cedex 3

27 avenue Valombrose

06107 Nice cedex 2

Keywords: Brown adipose tissue, UCP1, microRNAs, AGO2

Highlights:

- microRNA expression profile is globally upregulated in active BAT.

- AGO2 and microRNAs are enhanced in active BAT while unchanged in inactive tissue.

- The activation of brown adipocytes is associated to increased AGO2 levels.

- AGO2 knock-down is linked to reduced UCP1 levels and brown adipocyte function. 


\section{ABSTRACT}

MicroRNAs (miRNAs) are important modulators of thermogenic brown adipose tissue (BAT). They have been involved in its differentiation and hence its functioning. While different regulators of the miRNA machinery have been shown to be essential for BAT differentiation, little is known about their implication in BAT activation. The aim of this work was to evaluate the role of AGO2, the chief miRNA mediator, in BAT activation.

We took advantage of two non-genetic models of BAT activation to analyze the miRNA machinery and miRNA expression in BAT. We used principal component analysis (PCA) to obtain an overview of miRNA expression according to the BAT activation state. In vitro, we examined AGO2 expression during brown adipocyte differentiation and activation. Finally, we downregulated $\mathrm{AGO} 2$ to reveal its potential role in the thermogenic function of brown adipocytes.

PCA analysis allowed to cluster animals on their miRNA signature in active BAT. Moreover, hierarchical clustering showed a positive correlation between global upregulation of miRNA expression and active BAT. Consistently, the miRNA machinery, particularly AGO2, was upregulated in vivo in active BAT and in vitro in mature brown adipocytes. Finally, the partial loss-of-function of AGO2 in mature brown adipocytes is sufficient to lead to a diminished expression of UCP1 associated to a decreased uncoupled respiration.

Therefore, our study shows the potential contribution of AGO2 in BAT activation. Since BAT is a calorie-burning tissue these data have a translational potential in terms of therapeutic target in the field of altered fuel homeostasis associated to obesity and diabetes. 


\section{INTRODUCTION}

Organismal homeostasis allowing regulation of body weight and adiposity is achieved through a fine-tuned balance between energy expenditure and energy intake. Contrary to the white adipose tissue (WAT) specialized in energy storage, brown adipose tissue (BAT) mainly dissipates energy by producing heat via the perturbation of the mitochondrial electron transport chain through the tissue specific expression of uncoupling protein1 (UCP1), a process called non-shivering thermogenesis [1, 2]. This tissue is specialized in the maintenance of body temperature in response to cold, and in the dissipation of fuel excess under specific conditions $[1,3-5]$. As BAT appears to be present and active in various regions of the adult human body [6-10], it sparks speculation of novel treatments of obesity and/or diabetes by virtue of its energy-wasting function [10-13].

The development and function of brown adipocytes are tightly regulated by non-coding RNAs $[14,15]$. Among these non-coding RNAs are microRNAs (miRNAs) acting as single-stranded 20- to 22-nucleotide-long RNAs. Generally speaking, they regulate gene expression by specifically binding to the 3 ' untranslated region of targeted mRNAs to tailor the protein output by mRNA destabilization and/or translational repression [16, 17]. In animals, miRNAs are synthesized and regulated by a specific machinery, which includes as main players DROSHA, Exportin-5 (EXP5), DICER and Argonaute-2 (AGO2). The mammalian genome encodes several hundreds of miRNAs amongst which several have been implicated in cardinal cellular processes such as proliferation, differentiation and metabolism [16]. In the field of BAT metabolism, specific miRNAs including the miR-193b-365 cluster, miR-133 or miR-455 have been found to be involved in brown adipocyte differentiation fostering glucose and lipid oxidation [18-22]. At a more general level, the miRNA-processing machinery has been implicated in brown adipocyte determination and differentiation. In a pioneer study, Mori et al reported that DICER invalidation in BAT induces its inactivation [23]. Further, in vivo partial DICER deficiency in BAT predisposes mice to obesity-associated deterioration of glucose homeostasis, highlighting the importance of the miRNA machinery in the differentiation of brown adipocytes [24].

Despite these clear advances in our knowledge on the role of miRNAs and their machinery in BAT differentiation, a conceptual gap remains as far as the role of the miRNA machinery in BAT activation is concerned.

In this study, we examined two non-genetically modified rat models in which BAT is activated either by $\beta-3$ adrenergic receptor agonist treatment or as occurring at young age in BAT from fetal-programmed diabetic rats. In the latter, insulinopenic young offspring of rat dams exposed to a low protein diet (LP) during pregnancy and lactation benefit from metabolic adaptation 
through BAT activation securing normoglycemia [5]. Taking advantage of these models, together with additional cellular in vitro approaches, we sought to directly examine the miRNA machinery and particularly AGO2, the chief mediator of miRNA function, in BAT activation.

\section{MATERIALS AND METHODS}

\subsection{Animals}

All procedures were conducted in accordance with EU directives for animal experiments and INSERM guidelines and were approved by the Research Ministry (MESR 00825, MESR 0521, MESR-00500.02 and APAFIS 3897- 2016012217578333) and local ethics committee (CNREEA no. 28). The Wistar rats were provided by Janvier (Le Genest Saint Isle, France), housed two per cage and subjected to a $12-\mathrm{h}$ light/dark cycle at $22-23^{\circ} \mathrm{C}$, which is close to the rat thermoneutrality [25]. For the pharmacological BAT activation model, 3 month-old Wistar male rats were daily injected intraperitoneally with a $\beta-3$ adrenergic receptor agonist CL316, 243 (1 mg/kg in physiologic NaCl solution, C5976, Sigma-Aldrich) for 7 days. Control rats were injected with vehicle only. For the LP model, pregnant 200-250 g Wistar rats were fed during gestation and lactation with a control (C) diet (20\% [weight for weight] protein) or an isocaloric LP diet (8\% [weight for weight] protein) (Hope Farm, Woerden, the Netherlands) [5, 26]. After weaning at 4 weeks, male offspring were fed ad libitum with the animal facility standard diet. At least three different litters were studied in each group for all experiments [5, 27]. For adipose tissue-derived stromal vascular fraction (SVF) isolation, 3 month-old Wistar rats were used.

\subsection{Adipose tissue-derived SVF culture}

Animals were euthanized by the intraperitoneal injection of Dolethal $(1 \mathrm{~mL} / \mathrm{kg})$. Adipose tissuederived SVF culture was performed as described [28]. Briefly, interscapular brown fat depots (BAT) separated from the attached white adipose tissue (WAT) were excised, rinsed in bovine serum albumin (BSA)-buffer medium and minced. Minced samples were then digested in Dulbecco's modified Eagle's Medium (DMEM, Life Technologies) containing $2 \mathrm{mg} / \mathrm{mL}$ Type IV collagenase (Sigma-Aldrich, $125 \mathrm{U} / \mathrm{mg}$ ) and $20 \mathrm{mg} / \mathrm{mL}$ BSA (Fraction V, Fatty Acid Free, Ig Free, EUROMEDEX) with mild agitation for $45 \mathrm{~min}$ à $37^{\circ} \mathrm{C}$. After the addition of DMEM containing 10\% (v/v) FBS (Fetal Bovine Serum), digested tissues were filtered through 250, 100 and $37 \mu \mathrm{m}$ nylon mesh (SEFAR Nitex), and centrifuged for $10 \mathrm{~min}$ at $1000 \mathrm{rpm}$. The pellet containing SVF cells was submitted to red blood lysis buffer (Sigma-Aldrich). SVF cells were seeded and maintained in DMEM $4.5 \mathrm{~g} / \mathrm{L}$ glucose-glutamax-I (Life Technologies) containing $10 \%(v / v)$ FBS and 15 mM HEPES (Gibco, Life Technologies) until confluence. The brown 
adipocyte differentiation was induced in the same medium using a cocktail of $1 \mu \mathrm{M}$ dexamethasone (Sigma-Aldrich), $500 \mu \mathrm{M}$ isobutyl-methylxanthine (IBMX-Sigma), $860 \mathrm{nM}$ insulin (Novo Nordisk), $2 \mathrm{nM}$ triiodothyronine (T3, Sigma-Aldrich) and $1 \mu \mathrm{M}$ rosiglitazone (Cayman Chemical). After two days, dexamethasone and IBMX were removed and cells were maintained in a medium changed every two days containing $20 \mathrm{nM}$ insulin, $2 \mathrm{nM}$ thyroid hormone T3 and $1 \mu \mathrm{M}$ rosiglitazone for 5 to 8 additional days.

siRNA transfections were performed in iBAT-derived SVF mature adipocytes at day 7 with 50 nmol/L of siAGO2 (siRNA SMART Pool ON-Target plus Rat AGO2, 59117, Dharmacon) or siControl (ON-TARGETplus Non-targeting Pool D-001810-10, Dharmacon) according to manufacturer's procedure using Lipofectamine RNAimax (Thermofischer Scientific) adapted from previously described procedures $[29,30]$. Cells were analyzed $72 \mathrm{~h}$ after transfection corresponding to day 10 of differentiation.

\subsection{RNA extraction and RT-qPCR}

The procedures were carried out according to MIQE recommendations [31].Total RNA from iBAT, scWAT or adipose-derived SVF cells were isolated with TRIzol reagent (Invitrogen). For tissue dissociation, a Precellys homogenizer (Ozyme, St. Quentin, France) was used. Total RNA $(1 \mu \mathrm{g}$ ) was reverse transcribed with RT kit (Qiagen/Promega) and qPCR analyses performed with SYBR Green (StepOnePlus ABI Detector System). The cDNA amount used in each reaction was normalized to the housekeeping gene 36B4. The relative expression was determined using a comparative method of 2-ddCt and the relative abundance with 2-dCt. Primer sequences used are described in Supplementary Table 1.

\subsection{MiRNA expression profile}

miRNA quantitative PCR array analysis was performed using the rno-mirNome miRNA profiling kit (RA680A-1 for 390 rat-specific miRNAs or RA680B-1 for 723 rat-specific miRNAs, System Biosciences). Briefly, $1 \mu \mathrm{g}$ of total RNA for each sample was reverse transcribed with the Quanti-mir Kit (System Biosciences). The amplification of miRNAs was performed with miRNAspecific rat primers using SybrGreen technology (Applied Biosystem). Expression levels were normalized to U6 reference gene as endogenous control since its melting curve was more satisfactorily compared with that obtained for the two other reference genes. The relative expression was determined using a comparative method of 2-ddCt and the relative abundance with 2-dCt. Principal Component Analysis (PCA) plots based on detected miRNAs and 
hierarchical clustering analyses with significantly dysregulated miRNAs were created using Phantasus (https://artyomovlab.wustl.edu/phantasus/).

\subsection{Western blotting}

Homogenized iBAT or iBAT-derived SVF cells were processed for protein extraction and western blotting as described [23]. Antibody to AGO2 was from Cell Signaling Technology, to UCP1 from Calbiochem (Merck KGA, Darmstadt, Germany) and to tubulin from Sigma (St Louis, USA). Western blots were quantified by densitometry with Image Quant software.

\subsection{Oxygen consumption measurement}

For the respirometry quantifications, iBAT-derived SVF cells were seeded into Seahorse XFe96 microplate-based respirometry plates (Agilent) and grown to confluency in the proliferation medium. After 7 days of differentiation, cells were transfected. 72 hours posttransfection, medium was replaced by prewarmed unbuffered Seahorse Assay Medium (Agilent) supplemented with $2 \mathrm{mM}$ glutamine (Gibco, Life Technologies), $1 \mathrm{mM}$ pyruvate (Gibco, Life Technologies) and $10 \mathrm{mM}$ glucose, pH 7.4. Oxygen Consumption Rate (OCR) was determined using an XFe96 Extracellular Flux Analyzer at $37^{\circ} \mathrm{C}$ (Seahorse Bioscience, Agilent). Uncoupled and maximal OCR were determined using oligomycin (Sigma-Aldrich, 1.2 $\mu \mathrm{M})$ and FCCP injection (Sigma-Aldrich, $0.8 \mu \mathrm{M}$ ) after treatment or not with isoproterenol (Cayman Chemicals, $1 \mu \mathrm{M}$ ) incubations, and rotenone and antimycin A (Sigma-Aldrich, $1 \mu \mathrm{M}$ each) were used to inhibit Complex I and Complex III dependent respiration, respectively, to assess the contribution of non-mitochondrial respiration. All data presented are mean values +/- SEM of three independent experiments with 8-12 replicate wells each.

\subsection{Lipolysis assay}

$72 \mathrm{~h}$ post-transfection, cells were changed with medium containing $0.5 \%(\mathrm{w} / \mathrm{v})$ fatty acid-free BSA (Euromedex) and incubated with $1 \mu \mathrm{M}$ isoproterenol (Cayman Chemicals) during $1 \mathrm{~h} 30$. Glycerol content was analyzed in $50 \mu \mathrm{l}$ of incubating medium at the beginning and the end of the experiment. At the end of the experiment, cells were rinsed with PBS $1 \mathrm{X}$ and protein content was determined using BCA Protein assay (Interchim).

\subsection{Statistical analyses}

Significant differences between two groups were assessed by unpaired or paired Student's ttest and two-way ANOVA test followed by post hoc Fisher test when more than two conditions 
were analyzed. A p-value $<0.05$ was considered as statistically significant. All bars shown represent mean $+/$ - Standard Error Mean (SEM).

\section{RESULTS}

\subsection{The miRNA machinery and miRNAs are upregulated in drug-activated iBAT.}

To investigate whether the miRNA machinery is involved in the regulation of the iBAT activity, we daily intra-peritoneally injected 3 month-old control rats for 1 week with the $\beta-3$ adrenergic receptor agonist, CL316,243, well-known to activate brown adipocytes [4, 32]. As expected, an increase in the iBAT mass is observed in CL316,243-treated rats in addition to the key characteristics of an hyperactive BAT with rare lipid droplets associated with upregulated UCP1 expression (Supplementary Figure $1 \mathrm{~A}-\mathrm{E}$ ). By measuring gene expression of major players in the miRNA machinery we observed that DROSHA, EXP5 and AGO2 are increased in the iBAT of CL316,243-treated rats with the highest fold for AGO2 (Fig. 1A). AGO2 is also augmented at the protein level concomitantly with increased UCP1 protein (Fig. 1B). We then performed a global miRNA expression profile in this active iBAT using a quantitative PCRbased miRNA profiler for which $99 \%$ of 390 available rat-specific analyzed miRNAs were detected. Among these miRNAs, 38 miRNAs are dysregulated corresponding to $9.7 \%$ of detectable miRNAs in CL316,243-treated rats compared to controls. The principal component analysis (PCA) shows that biological replicates in each condition are clustered close together on the plot and reveals a distinct pattern of the miRNA expression profile between CL316,243treated rats and $\mathrm{NaCl}$-injected rats (Fig. $1 \mathrm{C}$ ). The volcano plot depicting the relationship between the fold change of the miRNA expression and their statistical significance shows that $74 \%$ of the significantly dysregulated miRNAs are upregulated in the iBAT of CL316,243treated rats, with 28 upregulated miRNAs for 10 downregulated miRNAs (Fig.1D, Supplementary Table 2). Specifically, the PCA plot and hierarchical clustering of these significantly dysregulated miRNAs clearly identify the two experimental groups (Supplementary Figure 1F-G), which are even more apart than in the analysis of all detected miRNAs (Fig.1.C). Moreover, the upregulated miRNAs are globally among the weakly expressed miRNAs in the iBAT, while the downregulated ones are among the most abundant ones (Supplementary Table 2). Taken as a whole, these data unveil that in active iBAT the over-all upregulation of miRNA expression occurs together with an augmented miRNA machinery, particularly concerning AGO2. 


\subsection{The expression of the miRNA machinery correlates with the iBAT activation state in LP progeny.}

We next took advantage of the LP model in which we have recently reported that the iBAT is a decisive determinant of metabolic dysregulation [5]. We observed that the gene expression levels of miRNA machinery elements, including DROSHA, EXP5, DICER and AGO2, are increased in the active iBAT of the young LP progeny compared to their controls (Fig. 2A), with the highest increment for AGO2. Importantly, in the inactive iBAT of the old LP progeny their gene expression levels are similar to those of the control progeny. However, in old LP progeny DICER stands out with a nearly significant decrease (Fig. 2B), which is consistent with a previous report [33]. In the young LP descendants, AGO2 is also increased at the protein level correlated with the increase in UCP1 (Fig. 2C). Importantly, both AGO2 and UCP1 show no difference in their protein expression levels in the iBAT of the 18 month-old LP progeny compared to their controls (Fig. 2D). Further, we measured the gene expression levels of the miRNA machinery in scWAT of young $C$ and LP descendants. We have previously published the absence of browning in the scWAT of young LP progeny [5]. Consistent with this we did not observe differences between both groups for any of the miRNA machinery actors (Supplementary Figure 2A). However, the surgical ablation of the iBAT in these LP animals was able to induce the expression of UCP1 in the scWAT [5]. Interestingly, the gene expression level of AGO2 is significantly augmented in the scWAT of the iBAT-ablated LP progeny compared to the sham-operated rats (Supplementary Figure 2B). To sum up, the increased expression of the miRNA machinery ties in with the active thermogenic state of the iBAT in young LP progeny and the browning of the scWAT in the iBAT-ablated LP progeny.

\subsection{In young LP progeny the upregulation of miRNAs in iBAT is linked to its active state}

We performed a side-by-side analysis of the miRNA expression profile between the active iBAT of young normoglycemic LP progenies and the inactive iBAT of old hyperglycemic LP progenies compared to their respective controls (Fig.3). We were able to detect respectively $90 \%$ and $95 \%$ of the 723 available rat-specific miRNAs screened. The PCA on all detected miRNAs clearly differentiates LP progeny samples from those from controls at 3 months of age (Fig. 3A), whereas they are mixed at 18 months of age (Fig. 3B). The volcano plot shows that $85 \%$ of miRNAs are upregulated in the iBAT of the young LP progeny, with 53 upregulated miRNAs and 9 downregulated ones (Fig. 3 C, Supplementary Table 3). In the iBAT of the old LP progeny three times less miRNAs are significantly dysregulated (Fig. 3 D). Consistent with the global analysis, both the PCA plot and hierarchical clustering of the significantly 
dysregulated miRNAs identify two clearly separated groups in young progenies, contrary to old progenies, having overlapping patterns. (Supplementary Figure 3A-D). Interestingly, upregulated miRNAs with the highest fold of induction are among the most weakly expressed in the IBAT of young progenies, and those downregulated are among the most robustly expressed (Supplementary Table 3). Remarkably, of the 62 miRNAs dysregulated in the young LP iBAT only 2 miRNAs remain dysregulated in the old LP iBAT but with a lower fold-change. The expression of the other miRNAs drops back to control levels (Supplementary Figure 3C$D$, Table 3). To summarize, these data gathered in the young LP progeny benefitting from metabolic adaptation through iBAT activation indicate that upregulation of miRNA expression and of its machinery is intimately associated to an active iBAT.

\subsection{AGO2 mRNA and protein levels are increased during brown adipocyte differentiation and activation.}

While generally speaking the miRNA machinery has already been implicated in the process of brown adipogenesis, notably for DICER [23], here we focused on AGO2. We firstly measured the gene expression level of the players in the miRNA machinery during the brown adipocyte differentiation of progenitor cells from SVF isolated from the iBAT of control rats (Fig. 4A). The characterization of these cells is presented in Supplementary Figure 4 showing notably the induction of UCP1 expression from day 0 to day 7 of the brown adipocyte differentiation process. We observed a progressive induction of the miRNA machinery gene expression during the brown differentiation for DICER and AGO2 with a significant fold in the terminal days (D5-7) when adipocytes become mature (Fig. 4B). Consistent with this, a gradual increase in AGO2 protein expression was found during brown adipocyte differentiation (Fig. 4C). Increased AGO2 gene expression was also seen in the terminal phase (D7) of brown-like adipocyte differentiation obtained with scWAT-derived SVF (Supplementary Figure 4F). Next, we were interested to establish whether AGO2 is involved in the activation of brown adipocytes by treating iBAT-derived mature adipocytes at day 7 of the differentiation with isoproterenol (Fig. 4D-E). Remarkably, AGO2 gene and protein levels are augmented after $6 \mathrm{~h}$ treatment with the $\beta 3$-adrenergic receptor-agonist isoproterenol concomitantly with the expected increase in UCP1 gene and protein levels. In aggregate, AGO2 augments not only during differentiation of brown adipocytes, but also during their activation. 


\subsection{AGO2 contributes to efficient mitochondrial respiration in brown adipocytes.}

To directly assess the involvement of AGO2 in brown adipocyte activation we transfected siRNA to AGO2 in mature iBAT-derived SVF adipocytes (Fig. 5A). $72 \mathrm{~h}$ post-transfection, AGO2 gene and protein expression levels are decreased by $50 \%$ (Fig. 5B-C). Interestingly, the inhibition of AGO2 causes a decrease in UCP1 gene and protein expression levels (Fig. 5B-C). To examine the impact of diminished UCP1 levels on brown adipocyte activity, lipolysis was analyzed by measuring glycerol content after isoproterenol treatment (Fig. 5D). No difference between siAGO2 and SiCTRL transfected cells was observed. We next evaluated the mitochondrial function by measuring the oxygen consumption rate (Fig. $5 \mathrm{E}-\mathrm{H}$ ). Strikingly, the downregulation of $\mathrm{AGO} 2$ leads to a significant drop in the basal oxygen consumption rate without affecting maximal mitochondrial respiration (Fig. 5 E-F). Moreover, uncoupled respiration, unstimulated but also after isoproterenol treatment, is decreased in siAGO2 transfected mature brown adipocytes (Fig. $5 \mathrm{G}-\mathrm{H}$ ). In conclusion, the transfection of siAGO2 in mature brown adipocytes leads to half inhibition of UCP1 expression resulting in a decrement in the basal mitochondria activity and the uncoupling activity. As a whole, the data are compatible with the idea that downregulation of AGO2 in mature brown adipocytes could result in a partial loss of their thermogenic activity.

\section{DISCUSSION}

BAT has received increasing attention the past decade owing to its ability to burn fuels through uncoupling of the mitochondrial proton gradient. Both in animals and humans, BAT content and activity are high in newborns but regress with aging. The understanding of the mechanisms by which BAT can be maintained in adulthood in an active state is hoped to lead to novel means to combat the development of metabolic disorders due to fuel excess. Our study unveils the potential role of the chief miRNA mediator, AGO2, $[16,17]$, in the activation of BAT. We found that among the different miRNA machinery regulators, AGO2 levels are increased with the highest fold in active iBAT of rats chronically-injected with $\beta$-adrenergic receptor agonist. Such treated rats are a well-accepted physiological model for BAT activation [4, 32]. Similarly, using the LP rat model in which we have previously shown that BAT plays an important role in energy homeostasis, we report now that AGO2 levels are also positively correlated to the iBAT activation state [5]. Interestingly, the increase in AGO2 is associated to the induction of low abundant miRNAs in iBAT. Remarkably, we found that after its gradual increase during brown adipogenesis, the AGO2 level further augments during the activation of mature brown adipocytes. To delve into the consequences of changes in AGO2 level we focused on BAT 
thermogenic activity in mature iBAT-derived SVF adipocytes. Of note, the siRNA-induced downregulation of AGO2 in mature brown adipocytes results in the decrease in UCP1 levels to the same extent. Consequently, the mitochondrial oxygen consumption is diminished in basal condition and after oligomycin treatment in presence or in absence of isoproterenol. As oligomycin allowed the evaluation of respiration uncoupled to ATP synthesis, this measurement partly reflects the UCP1 uncoupling activity of mature brown adipocytes.

Among the chief proteins of the miRNA machinery, DICER and DGCR8 have previously been shown to play a key role in adipocyte metabolism [23, 33-35]. Indeed, the partial deletion of DICER specifically in BAT, to comparable levels observed during aging or obesity, alters the differentiation of brown adipocytes and consequently the function of the tissue, eventuating in deterioration of organismal glucose homeostasis [24]. In particular, this deletion coincides with global miRNA downregulation associated with decreased BAT activity, leading to increased sensitivity to cold and high fat diet in these mice [24]. In this study, the comparative analysis of miRNA expression profile in iBAT from different animal models has shown that long-lived mice benefit from upregulation of miRNAs with more active BAT, while progeroid mice present downregulation of these miRNAs with inactive BAT [24]. These data are consistent with our work demonstrating the upregulation of more than $70 \%$ of miRNAs in the active iBAT of both CL316,243-injected rats, and of young LP rat progeny. In stark contrast, this miRNA set has returned to control levels in the inactive iBAT of old LP progeny. Importantly, among the key elements of the miRNA machinery AGO2 is systematically robustly increased in active BAT of both of our rat models, whereas the others, including DICER, are less impacted. This observation fits with the idea that the augmented number of miRNAs need more AGO2 to be functional.

Using differentiated adipocytes, we avoid possible confounding effects of AGO2 on the process of adipogenesis. Indeed, a previous study performed in 3T3-L1 preadipocytes has found that $A G O 2$ downregulation does not substantially influence white adipogenesis. MiRNAs previously described to be involved in brown adipocyte terminal differentiation or browning induction, such as miR133, miR-27, miR-378, miR455 or miR193b-365 cluster, are well expressed in the active iBAT from CL316,243-injected rats or young LP progeny [18-22]. However, no significantly increased expression was observed for these miRNAs compared to their respective controls, while AGO2 levels are enhanced. In fact, the two situations that we studied correspond to BAT activation models through either pharmacological drug treatment or adaptive response rather than models of BAT differentiation or of WAT browning induction. Indeed, to observe clearly detectable WAT browning in these models CL316,243 treatment has to be longer than 7 days $[32,36]$ or iBAT has to be removed in the LP progeny [5]. This 
could explain why miRNAs involved in BAT terminal differentiation or browning induction are not enhanced in iBAT of these models. Taken as a whole our data suggest the involvement of AGO2 in the activation of iBAT rather than in the promotion of brown tissue differentiation. Interestingly, the promoter of AGO2 gene displays predicted binding sites for CREB1, which is induced by $\beta$-adrenergic stimulation. Moreover, noradrenaline urine levels are significantly increased in young LP progeny [5]. Further investigations are required to decipher whether AGO2 levels are increased via $\beta$-adrenergic activation of CREB1 to modulate UCP1 levels, possibly by miRNAs.

Importantly, in mammals BAT development occurs predominantly at the end of gestation [13, $37,38]$. It becomes fully functional at birth, when it is needed for the effective adaptation to the extra-uterine environment. This suggests that the in utero environment plays an important role in preparing the peri-natal functional development of BAT. We have recently reported that young offspring of rat dams exposed to a LP diet during pregnancy and lactation benefit from metabolic adaptation through BAT activation allowing the maintenance of organismal glucose homeostasis despite a pronounced insulin secretion defect [5]. We have provided solid evidence that the normoglycemia, despite collapsed insulin secretion, seen in the young LP progeny is likely due, for the greater part, to hyperactive BAT. Observations concerning developmental programming of adult disease are being gathered in favor of a key role for miRNAs in gene expression regulation [26, 39-41]. Here, we show that the increase in miRNA machinery, particularly AGO2, is closely associated to active iBAT, which is instrumental in maintaining glucose homeostasis in young LP progeny. Our data dovetail with recent reports showing AGO2 involvement in the adaptive response to face an environmental stress in $\beta$ cells [42] or in hepatocytes [43, 44]. Indeed, the loss of AGO2 in $\beta$-cells during insulin resistance inhibits compensatory $\beta$-cell hyperplasia [42] and in hepatocytes, it leads to reduced hepatic glucose production coupled to decreased fasting glycemia $[43,44]$. Note that in the study by Nakamura et al. in mice the liver-specific knockout of AGO2 leads to increased mitochondrial metabolism [44], which is different from our observations in rats showing partial siRNA-induced AGO2 insufficiency in BAT to be associated to decreased mitochondrial respiration. This divergence could be due to several factors including the obviously different role of the liver versus the BAT in energy expenditure, the organ specific miRNA targets as well as miRNA environment affecting the miRNA/AGO2 interactions and the animal species. To summarize, our study pushes forward the above-mentioned publications by further highlighting the crucial importance of AGO2, the key RNA-binding protein mediating miRNA functioning, in adaptive responses to environmental stress. Therefore, we would like to suggest that a deleterious intra-uterine fetal setting or a post-natal environmental stress could 
reprogram BAT's physiology and metabolism through the miRNA machinery to face forthcoming or present energetic challenges.

\section{CONCLUSION}

The key message of our work is that the AGO2 protein potentially contributes to BAT activation. The coordinated increase in AGO2 protein and in miRNA expression correlates with the active state of iBAT in two non-genetic rat models. Conversely, the downregulation of AGO2 in mature brown adipocytes induces a phenotype compatible with decreased thermogenic activity. While the fundamental mechanistic underpinnings have to be parsed out, our findings have translational potential in the field of altered fuel homeostasis associated to obesity and diabetes. It stands to reason that the discovery of means to enhance the miRNA machinery leading to BAT activation could be a promising asset for future therapies of conditions with dysregulated energetic metabolism.

\section{ACKNOWLEDGEMENTS}

The authors thank IRCAN animal housing facility and genomics core facility.

\section{DECLARATION OF INTERESTS}

The authors declare that there is no conflict of interest associated with the manuscript.

\section{AUTHOR CONTRIBUTIONS}

E.R., O.D., D.F.P. designed the study, researched data, and contributed to discussions and manuscript. N.G. researched data. E.V.O. designed the study, contributed to the discussions and manuscript. C.H. designed the study, researched data, and contributed to discussions and manuscript.

\section{FUNDING}

E.V.O team was supported by Inserm, University Côte d'Azur, Conseil Régional PACA, Conseil Général des Alpes-Maritimes, Aviesan/AstraZeneca, "Diabetes and the vessel wall injury" program, by the Agence Nationale de la Recherche (ANR) through ANRRPV12004AAA (DIAMIR) 'Investments for the Future' LABEX SIGNALIFE \#ANR-11-LABX0028-01, European Foundation for the Study of Diabetes (EFSD/Lilly; European Diabetes Research Program). EVO team members are affiliated to the FHU OncoAge (http://www.oncoage.org/). 


\section{REFERENCES}

[1] Cannon B., Nedergaard J., 2004. Brown adipose tissue: function and physiological significance. Physiological reviews 84:277-359.

[2] Townsend K.L., Tseng Y.H., 2014. Brown fat fuel utilization and thermogenesis. Trends in endocrinology and metabolism: TEM 25:168-177.

[3] Schulz T.J., Tseng Y.H., 2013. Brown adipose tissue: development, metabolism and beyond. The Biochemical journal 453:167-178.

[4] Pradhan R.N., Zachara M., Deplancke B., 2017. A systems perspective on brown adipogenesis and metabolic activation. Obesity reviews : an official journal of the International Association for the Study of Obesity 18 Suppl 1:65-81.

[5] Dumortier O., Roger E., Pisani D.F., Casamento V., Gautier N., Lebrun P., Johnston H., Lopez P., Amri E.Z., Jousse C., Fafournoux P., Prentki M., Hinault C., Van Obberghen E., 2017. Age-Dependent Control of Energy Homeostasis by Brown Adipose Tissue in Progeny Subjected to Maternal Diet-Induced Fetal Programming. Diabetes 66:627-639.

[6] Cypess A.M., Lehman S., Williams G., Tal I., Rodman D., Goldfine A.B., Kuo F.C., Palmer E.L., Tseng Y.H., Doria A., Kolodny G.M., Kahn C.R., 2009. Identification and importance of brown adipose tissue in adult humans. The New England journal of medicine 360:1509-1517.

[7] Saito M., Okamatsu-Ogura Y., Matsushita M., Watanabe K., Yoneshiro T., Nio-Kobayashi J., Iwanaga T., Miyagawa M., Kameya T., Nakada K., Kawai Y., Tsujisaki M., 2009. High incidence of metabolically active brown adipose tissue in healthy adult humans: effects of cold exposure and adiposity. Diabetes 58:1526-1531.

[8] van Marken Lichtenbelt W.D., Vanhommerig J.W., Smulders N.M., Drossaerts J.M., Kemerink G.J., Bouvy N.D., Schrauwen P., Teule G.J., 2009. Cold-activated brown adipose tissue in healthy men. The New England journal of medicine 360:1500-1508.

[9] Virtanen K.A., Lidell M.E., Orava J., Heglind M., Westergren R., Niemi T., Taittonen M., Laine J., Savisto N.J., Enerback S., Nuutila P., 2009. Functional brown adipose tissue in healthy adults. The New England journal of medicine 360:1518-1525.

[10] Chondronikola M., Volpi E., Borsheim E., Porter C., Saraf M.K., Annamalai P., Yfanti C., Chao T., Wong D., Shinoda K., Labbe S.M., Hurren N.M., Cesani F., Kajimura S., Sidossis L.S., 2016. Brown Adipose Tissue Activation Is Linked to Distinct Systemic Effects on Lipid Metabolism in Humans. Cell metabolism 23:1200-1206.

[11] Mukherjee J., Baranwal A., Schade K.N., 2016. Classification of Therapeutic and Experimental Drugs for Brown Adipose Tissue Activation: Potential Treatment Strategies for Diabetes and Obesity. Current diabetes reviews 12:414-428.

[12] Thyagarajan B., Foster M.T., 2017. Beiging of white adipose tissue as a therapeutic strategy for weight loss in humans. Hormone molecular biology and clinical investigation 31.

[13] Betz M.J., Enerback S., 2015. Human Brown Adipose Tissue: What We Have Learned So Far. Diabetes 64:2352-2360.

[14] Amri E.Z., Scheideler M., 2017. Small non coding RNAs in adipocyte biology and obesity. Molecular and cellular endocrinology 456:87-94.

[15] Goody D., Pfeifer A., 2018. MicroRNAs in brown and beige fat. Biochimica et biophysica acta.

[16] Bartel D.P., 2018. Metazoan MicroRNAs. Cell 173:20-51. 
[17] Creugny A., Fender A., Pfeffer S., 2018. Regulation of primary microRNA processing. FEBS letters 592:1980-1996.

[18] Sun L., Xie H., Mori M.A., Alexander R., Yuan B., Hattangadi S.M., Liu Q., Kahn C.R., Lodish H.F., 2011. Mir193b-365 is essential for brown fat differentiation. Nature cell biology 13:958-965.

[19] Trajkovski M., Ahmed K., Esau C.C., Stoffel M., 2012. MyomiR-133 regulates brown fat differentiation through Prdm16. Nature cell biology 14:1330-1335.

[20] Zhang H., Guan M., Townsend K.L., Huang T.L., An D., Yan X., Xue R., Schulz T.J., Winnay J., Mori M., Hirshman M.F., Kristiansen K., Tsang J.S., White A.P., Cypess A.M., Goodyear L.J., Tseng Y.H., 2015. MicroRNA-455 regulates brown adipogenesis via a novel HIF1an-AMPK-PGC1alpha signaling network. EMBO reports 16:1378-1393.

[21] Price N.L., Fernandez-Hernando C., 2016. miRNA regulation of white and brown adipose tissue differentiation and function. Biochimica et biophysica acta 1861:2104-2110.

[22] Chen Y., Pan R., Pfeifer A., 2017. Regulation of brown and beige fat by microRNAs. Pharmacology \& therapeutics 170:1-7.

[23] Mori M.A., Thomou T., Boucher J., Lee K.Y., Lallukka S., Kim J.K., Torriani M., YkiJarvinen H., Grinspoon S.K., Cypess A.M., Kahn C.R., 2014. Altered miRNA processing disrupts brown/white adipocyte determination and associates with lipodystrophy. The Journal of clinical investigation 124:3339-3351.

[24] Oliverio M., Schmidt E., Mauer J., Baitzel C., Hansmeier N., Khani S., Konieczka S., Pradas-Juni M., Brodesser S., Van T.M., Bartsch D., Bronneke H.S., Heine M., Hilpert H., Tarcitano E., Garinis G.A., Frommolt P., Heeren J., Mori M.A., Bruning J.C., Kornfeld J.W., 2016. Dicer1-miR-328-Bace1 signalling controls brown adipose tissue differentiation and function. Nature cell biology 18:328-336.

[25] Cannon B., Nedergaard J., 2011. Nonshivering thermogenesis and its adequate measurement in metabolic studies. J Exp Biol 214:242-253.

[26] Dumortier O., Hinault C., Gautier N., Patouraux S., Casamento V., Van Obberghen E., 2014. Maternal protein restriction leads to pancreatic failure in offspring: role of misexpressed microRNA-375. Diabetes 63:3416-3427.

[27] Rothwell N.J., Stock M.J., 1989. Surgical removal of brown fat results in rapid and complete compensation by other depots. The American journal of physiology 257:R253-258.

[28] Pisani D.F., Beranger G.E., Corinus A., Giroud M., Ghandour R.A., Altirriba J., Chambard J.C., Mazure N.M., Bendahhou S., Duranton C., Michiels J.F., Frontini A., Rohner-Jeanrenaud F., Cinti S., Christian M., Barhanin J., Amri E.Z., 2016. The K+ channel TASK1 modulates beta-adrenergic response in brown adipose tissue through the mineralocorticoid receptor pathway. FASEB journal : official publication of the Federation of American Societies for Experimental Biology 30:909-922.

[29] Karbiener M., Neuhold C., Opriessnig P., Prokesch A., Bogner-Strauss J.G., Scheideler M., 2011. MicroRNA-30c promotes human adipocyte differentiation and co-represses PAl-1 and ALK2. RNA Biol 8:850-860.

[30] Lundh M., Plucinska K., Isidor M.S., Petersen P.S.S., Emanuelli B., 2017. Bidirectional manipulation of gene expression in adipocytes using CRISPRa and siRNA. Molecular metabolism 6:1313-1320.

[31] Bustin S.A., Benes V., Garson J.A., Hellemans J., Huggett J., Kubista M., Mueller R., Nolan T., Pfaffl M.W., Shipley G.L., Vandesompele J., Wittwer C.T., 2009. The MIQE guidelines: minimum information for publication of quantitative real-time PCR experiments. Clinical chemistry 55:611-622. 
[32] Himms-Hagen J., Cui J., Danforth E., Jr., Taatjes D.J., Lang S.S., Waters B.L., Claus T.H., 1994. Effect of CL-316,243, a thermogenic beta 3-agonist, on energy balance and brown and white adipose tissues in rats. The American journal of physiology 266:R1371-1382.

[33] Reis F.C., Branquinho J.L., Brandao B.B., Guerra B.A., Silva I.D., Frontini A., Thomou T., Sartini L., Cinti S., Kahn C.R., Festuccia W.T., Kowaltowski A.J., Mori M.A., 2016. Fat-specific Dicer deficiency accelerates aging and mitigates several effects of dietary restriction in mice. Aging 8:1201-1222.

[34] Mudhasani R., Imbalzano A.N., Jones S.N., 2010. An essential role for Dicer in adipocyte differentiation. Journal of cellular biochemistry 110:812-816.

[35] Mudhasani R., Puri V., Hoover K., Czech M.P., Imbalzano A.N., Jones S.N., 2011. Dicer is required for the formation of white but not brown adipose tissue. Journal of cellular physiology 226:1399-1406.

[36] Ghorbani M., Teimourian S., Farzad R., AsI N.N., 2015. Apparent histological changes of adipocytes after treatment with $\mathrm{CL} 316,243$, a beta-3-adrenergic receptor agonist. Drug design, development and therapy 9:669-676.

[37] Frontini A., Cinti S., 2010. Distribution and development of brown adipocytes in the murine and human adipose organ. Cell metabolism 11:253-256.

[38] Schosserer M., Grillari J., Wolfrum C., Scheideler M., 2018. Age-Induced Changes in White, Brite, and Brown Adipose Depots: A Mini-Review. Gerontology 64:229-236.

[39] Barres R., Zierath J.R., 2016. The role of diet and exercise in the transgenerational epigenetic landscape of T2DM. Nature reviews. Endocrinology 12:441-451.

[40] Marciniak A., Patro-Malysza J., Kimber-Trojnar Z., Marciniak B., Oleszczuk J., Leszczynska-Gorzelak B., 2017. Fetal programming of the metabolic syndrome. Taiwanese journal of obstetrics \& gynecology 56:133-138.

[41] Sutton E.F., Gilmore L.A., Dunger D.B., Heijmans B.T., Hivert M.F., Ling C., Martinez J.A., Ozanne S.E., Simmons R.A., Szyf M., Waterland R.A., Redman L.M., Ravussin E., 2016. Developmental programming: State-of-the-science and future directions-Summary from a Pennington Biomedical symposium. Obesity 24:1018-1026.

[42] Tattikota S.G., Rathjen T., McAnulty S.J., Wessels H.H., Akerman I., van de Bunt M., Hausser J., Esguerra J.L., Musahl A., Pandey A.K., You X., Chen W., Herrera P.L., Johnson P.R., O'Carroll D., Eliasson L., Zavolan M., Gloyn A.L., Ferrer J., Shalom-Feuerstein R., Aberdam D., Poy M.N., 2014. Argonaute2 mediates compensatory expansion of the pancreatic beta cell. Cell metabolism 19:122-134.

[43] Yan X., Wang Z., Bishop C.A., Weitkunat K., Feng X., Tarbier M., Luo J., Friedlander M.R., Burkhardt R., Klaus S., Willnow T.E., Poy M.N., 2018. Control of hepatic gluconeogenesis by Argonaute2. Molecular metabolism.

[44] Zhang C., Seo J., Murakami K., Salem E.S.B., Bernhard E., Borra V.J., Choi K., Yuan C.L., Chan C.C., Chen X., Huang T., Weirauch M.T., Divanovic S., Qi N.R., Thomas H.E., Mercer C.A., Siomi H., Nakamura T., 2018. Hepatic Ago2-mediated RNA silencing controls energy metabolism linked to AMPK activation and obesity-associated pathophysiology. Nature communications 9:3658. 


\section{FIGURE LEGENDS}

Figure 1: miRNA machinery and miRNAs are upregulated in iBAT of rats chronicallyinjected with $\beta$-adrenergic receptor agonist. 3 month-old rats were daily intraperitoneally injected with $\mathrm{CL} 316,243(1 \mathrm{mg} / \mathrm{kg})$ or a saline solution $(\mathrm{NaCl} 0.9 \% \mathrm{w} / \mathrm{v})(\mathrm{n}=4)$. A: Relative mRNA expression levels of miRNA machinery. B: Immunoblots of AGO2, UCP1 and tubulin on iBAT protein lysates and its quantification. C: Global view of miRNA expression by using PCA plot. Clustering of samples are indicated by ellipses. D: Volcano plot showing the fold change in the expression of all detected miRNAs according to their p-value. The solid horizontal line indicates zero change in miRNA expression, the points above correspond to upregulated miRNAs while the points below are downregulated miRNAs. Data points to the right of the dotted line are significant $(p \leq 0.05)$. Data are presented as mean $+/-S E M$. * $p$-value $<0.05$.

Figure 2: The miRNA machinery is increased in the active iBAT of young LP progeny but unchanged in the inactive iBAT of old LP progeny. A and B: Relative mRNA expression levels of miRNA machinery from iBAT of C and LP progenies at 3 months $(n=9)$ and 18 months of age $(n=6)$. Data are normalized to 36B4 mRNA and expressed in arbitrary units. C and D: Immunoblots of AGO2, UCP1 and tubulin in iBAT protein lysates and its quantification at $(C) 3$ - and 18 -months $(n=4)$. Data are presented as mean $+/-$ SEM. * $p$-value $<0.05$.

Figure 3: The miRNA expression profile displays a specific signature for the active iBAT of young LP progeny. miRNA expression analysis in iBAT of 3 month-old $C$ and LP progenies $(n=3 / 4)$ and 18 month-old $C$ and LP progenies. A and B: Global view of miRNA expression by using PCA plot. Clustering of samples are indicated by ellipses. $\mathbf{C}$ and D: Volcano plot showing the fold change in the expression of detected miRNAs according to their $p$-value. The solid horizontal line indicates zero change in miRNA expression, the points above correspond to upregulated miRNAs while the points below are downregulated miRNAs. Data points to the right of the dotted line are significant $(p \leq 0.05)$.

Figure 4: The miRNA machinery, particularly AGO2, is upregulated during brown adipocyte differentiation and activation. A: Scheme of the brown adipocyte differentiation stages from SVF progenitors isolated from iBAT during 7 days (D0 to D7). B: Relative abundance of mRNA expression of miRNA machinery in iBAT-derived SVF during brown 
adipocyte differentiation $(n=5)$. Data are normalized to 36B4 mRNA and expressed in arbitrary units. C: Immunoblots of AGO2 and tubulin and its quantification in protein lysates from iBATderived SVF during brown adipocyte differentiation $(n=3)$. D: Relative mRNA expression levels of AGO2 and UCP1 in iBAT-derived SVF mature brown adipocytes treated at D7 with or without $1 \mu \mathrm{M}$ isoproterenol during 6h (n=3). E: Immunoblots of $\mathrm{AGO} 2$ and tubulin and its quantification in protein lysates from iBAT-derived SVF mature brown adipocytes treated at D7 with or without $1 \mu \mathrm{M}$ isoproterenol during $6 \mathrm{~h}(\mathrm{n}=3)$. Data are presented as mean +/- SEM. * $\mathrm{p}$ value $<0.05$

Figure 5: The partial inhibition of AGO2 in mature brown adipocytes impacts their thermogenic function.

A: Scheme of AGO2 siRNA transfection at day 7 in iBAT-derived SVF mature brown adipocytes for $72 \mathrm{~h}$. B: Relative mRNA expression levels of miRNA machinery and UCP1. Data are normalized to 36B4 mRNA and expressed in arbitrary units $(n=5)$. C: Immunoblots of AGO2, UCP1 and tubulin and their quantification ( $n=3)$. D: Glycerol release after a $1 \mathrm{~h} 30$ incubation without or with $1 \mu \mathrm{mol} / \mathrm{L}$ isoproterenol (ISO) $(n=3)$. Data are expressed per milligram of protein. E-H: Representative histograms obtained for oxygen consumption measurements $(n=3)$. Histograms show $(E)$ mitochondrial respiration and $(F)$ maximal respiration values under basal condition, $(\mathbf{G})$ shows unstimulated and $(\mathbf{H})$ isoproterenolstimulated uncoupled mitochondrial respiration. Data are presented as mean $+/$ - SEM. * $\mathrm{p}$-value $<0.05$. 
A

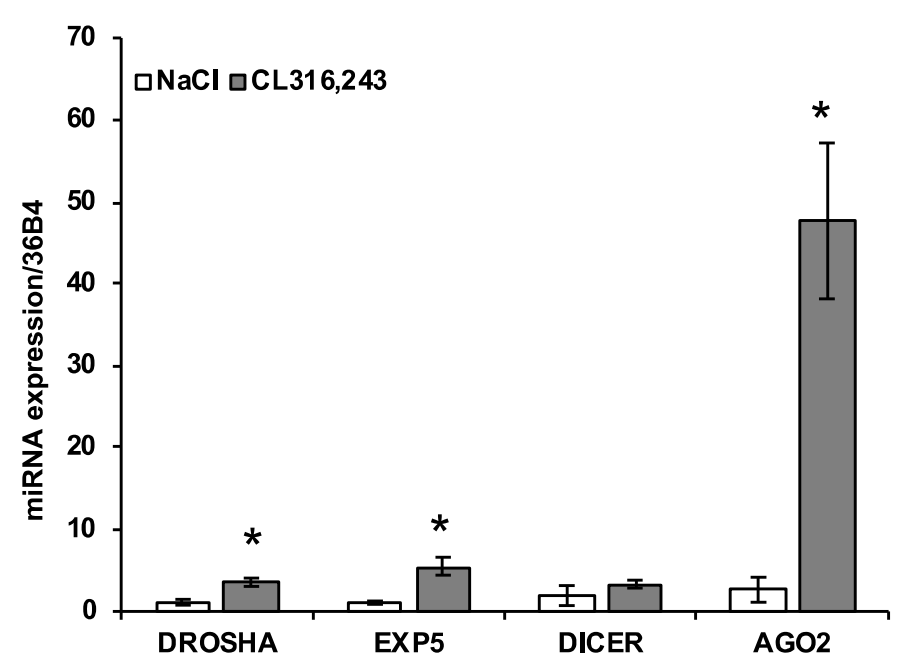

C

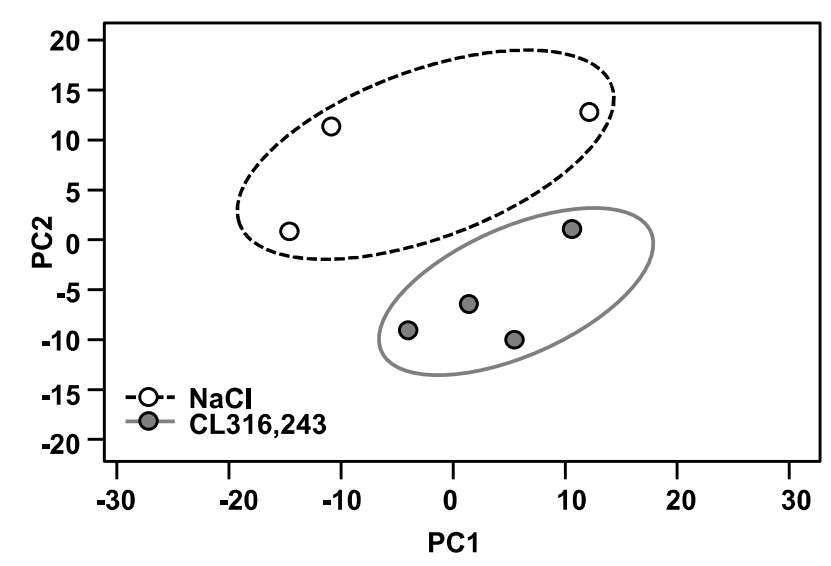

B
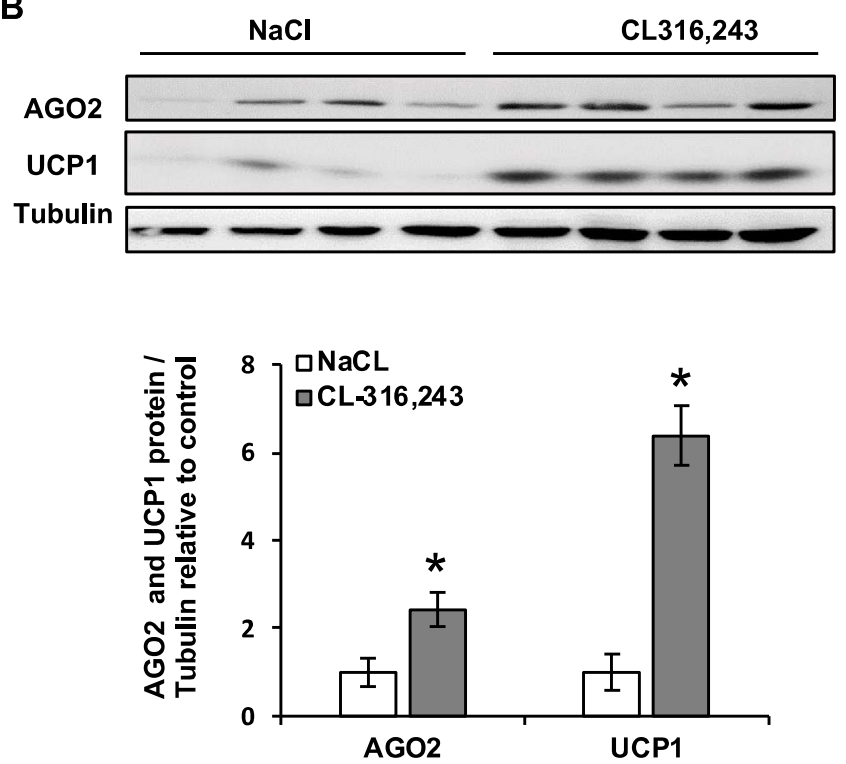

D

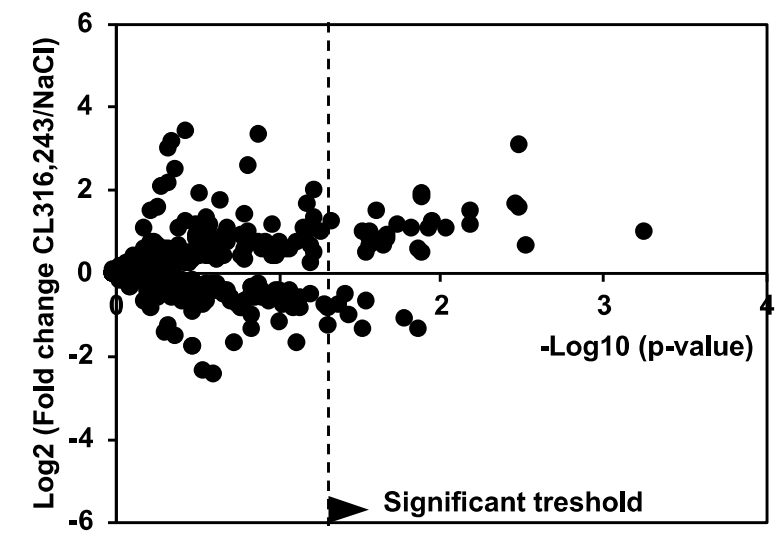

Figure 1 
iBAT - 3 months

A

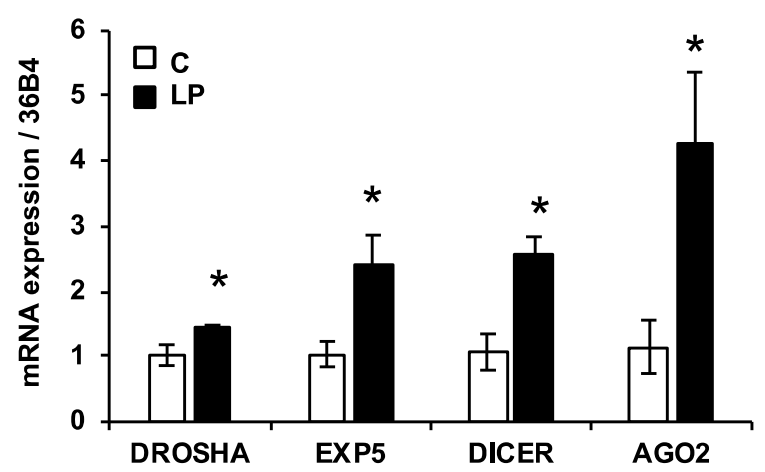

C
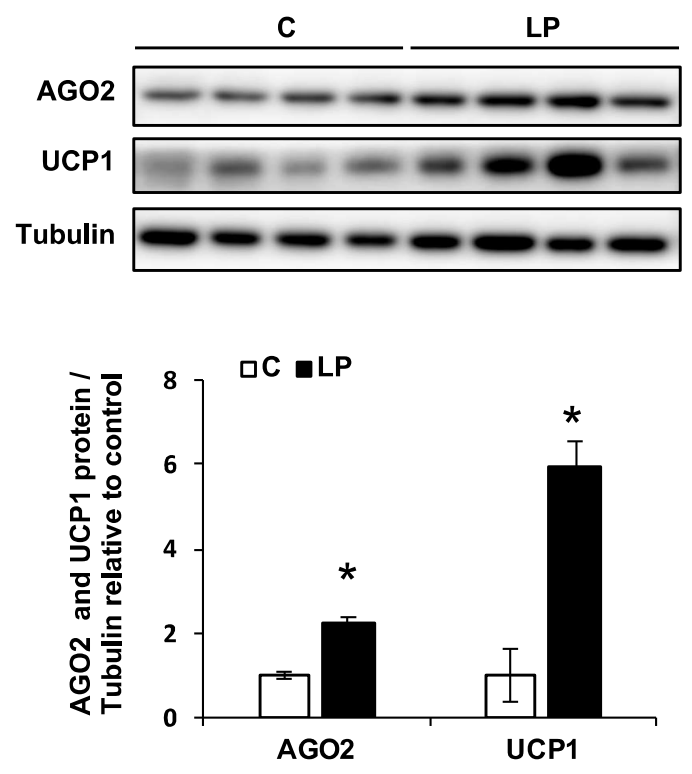

B

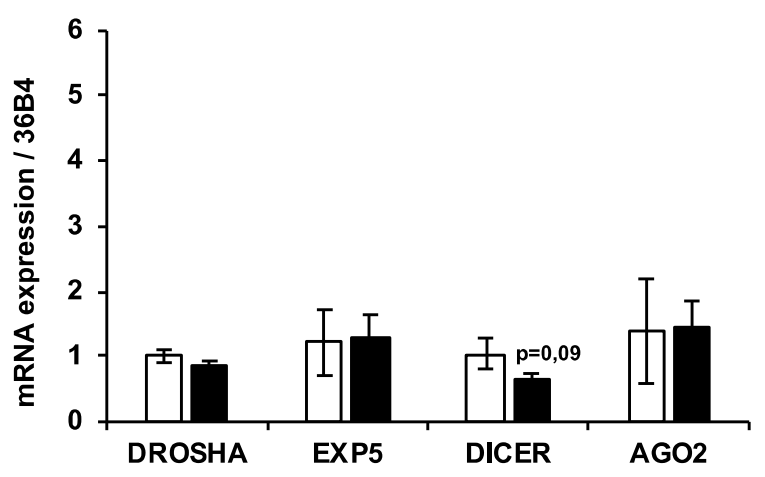

D
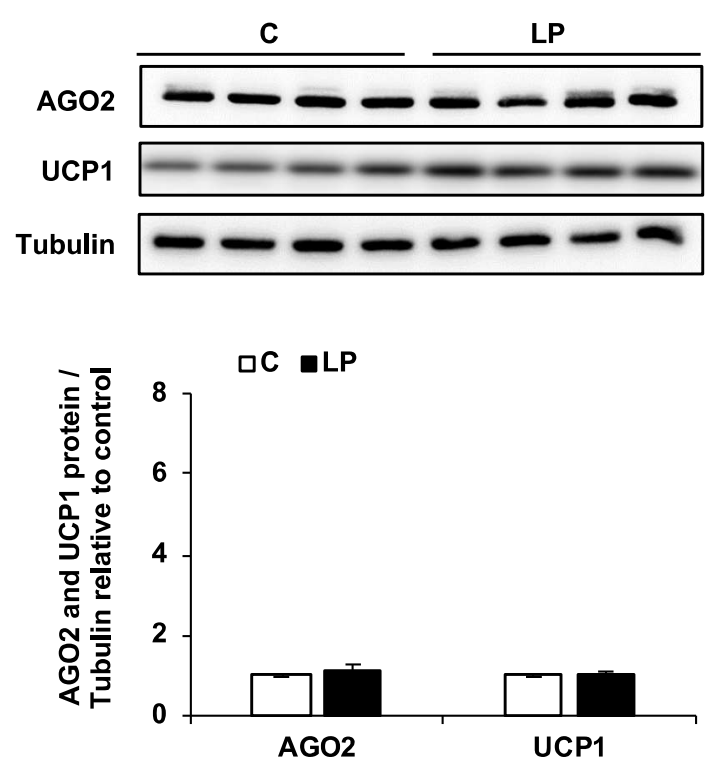

Figure 2 
IBAT - 3 months

A

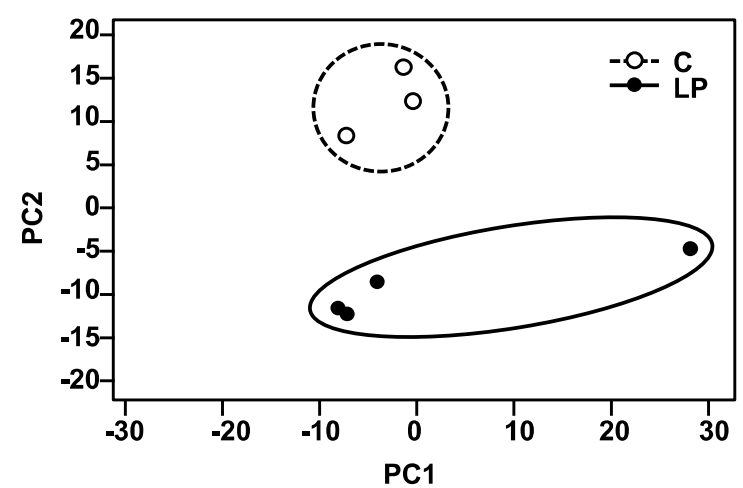

C

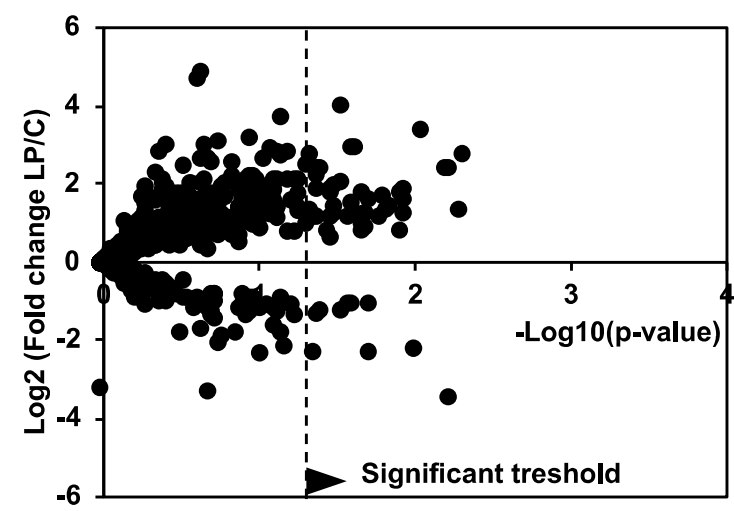

IBAT - 18 months

B

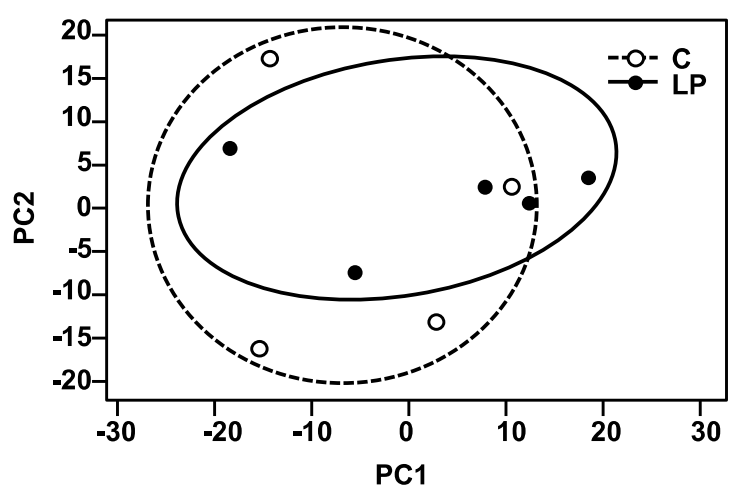

D

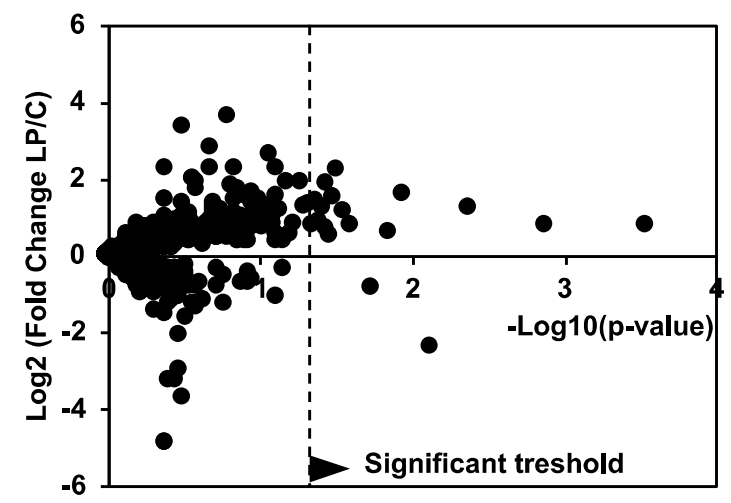

Figure 3 
A

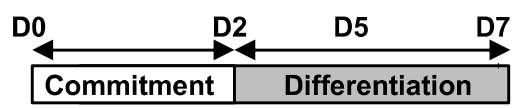

iBAT-derivedSVF

Brown adipocytes

B

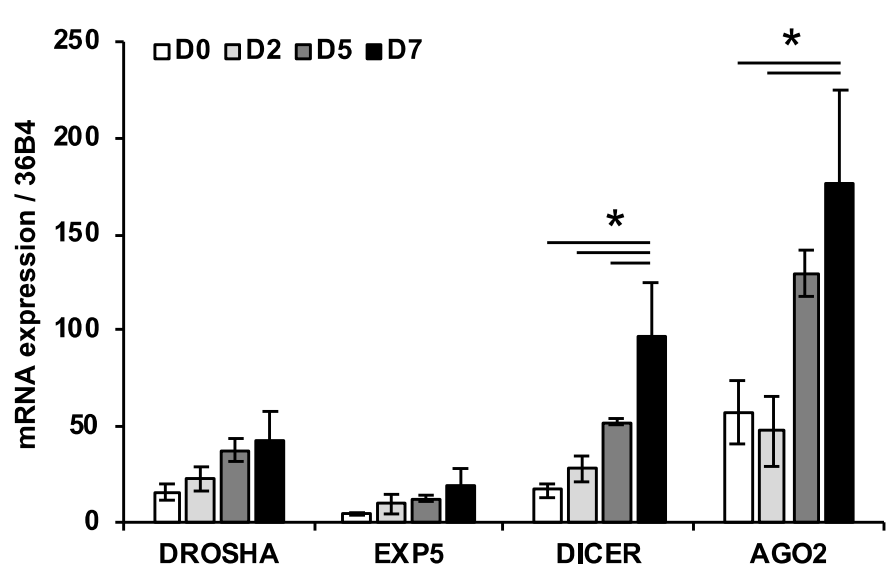

D

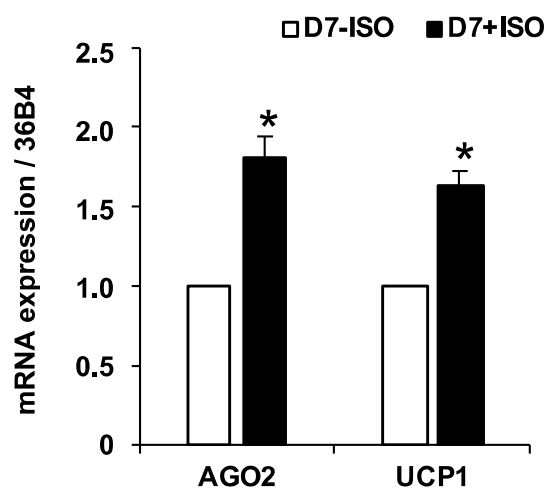

C
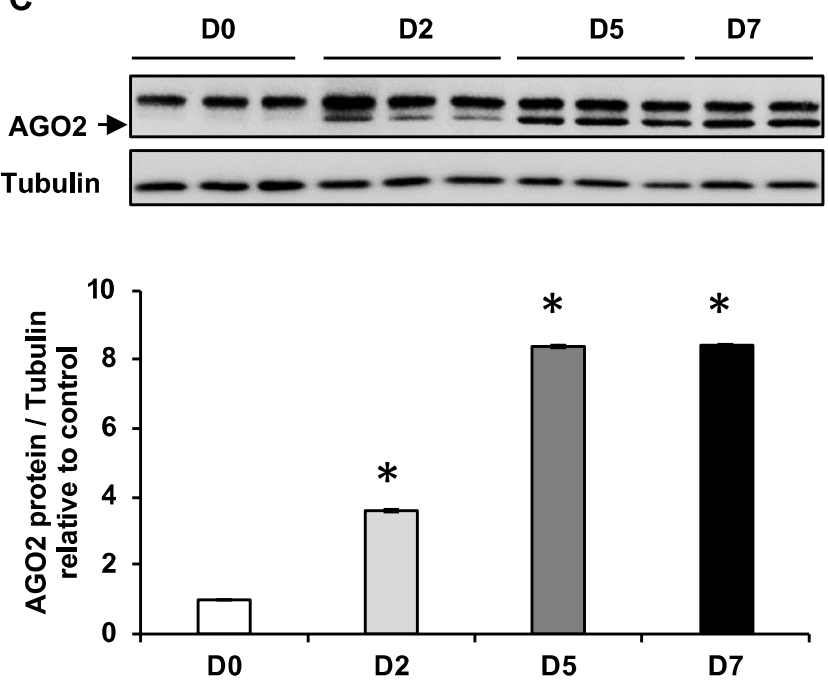

E

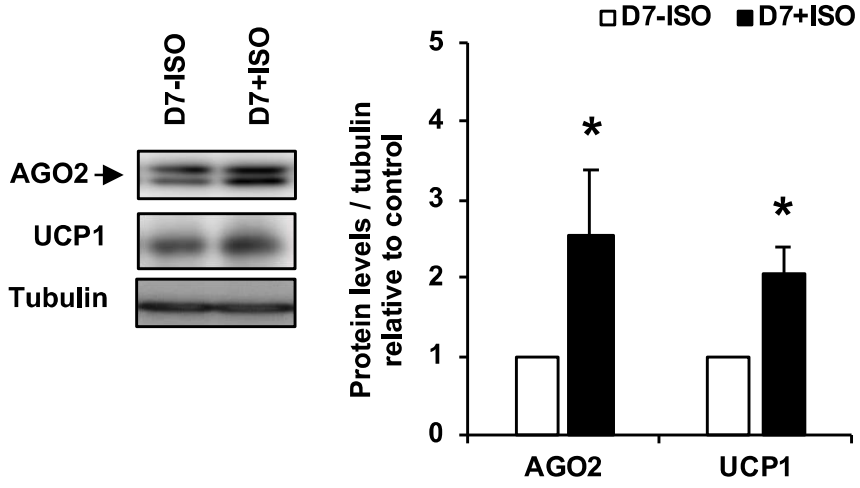

Figure 4 
A
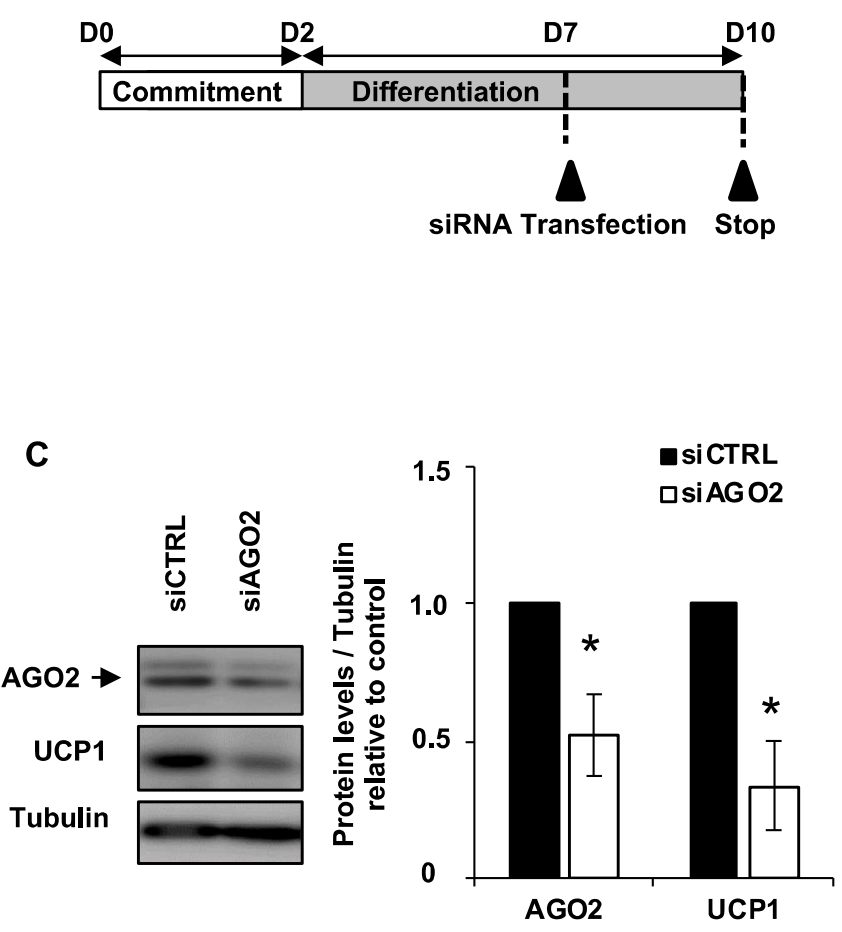

E

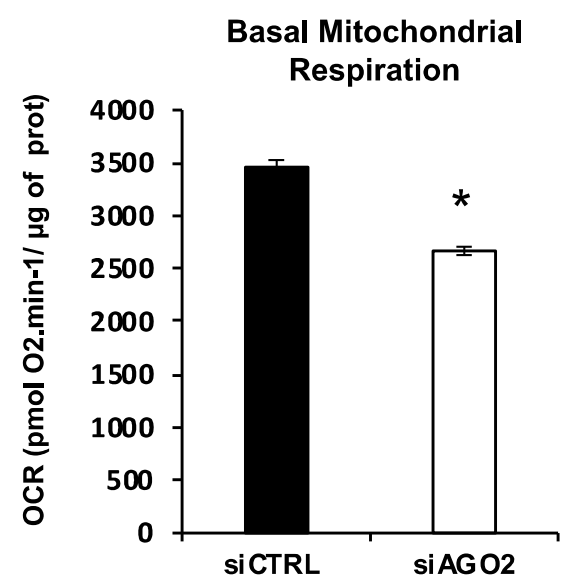

G

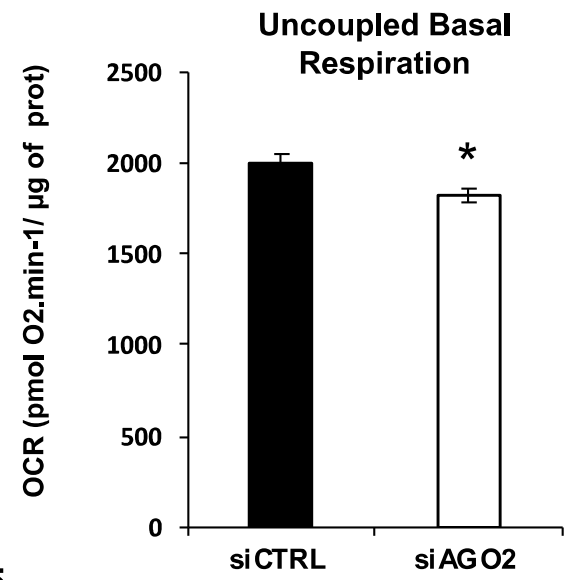

B

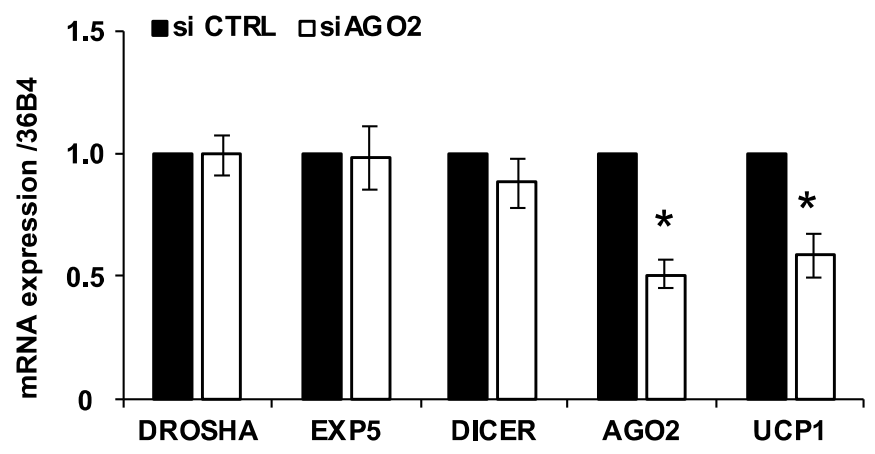

D

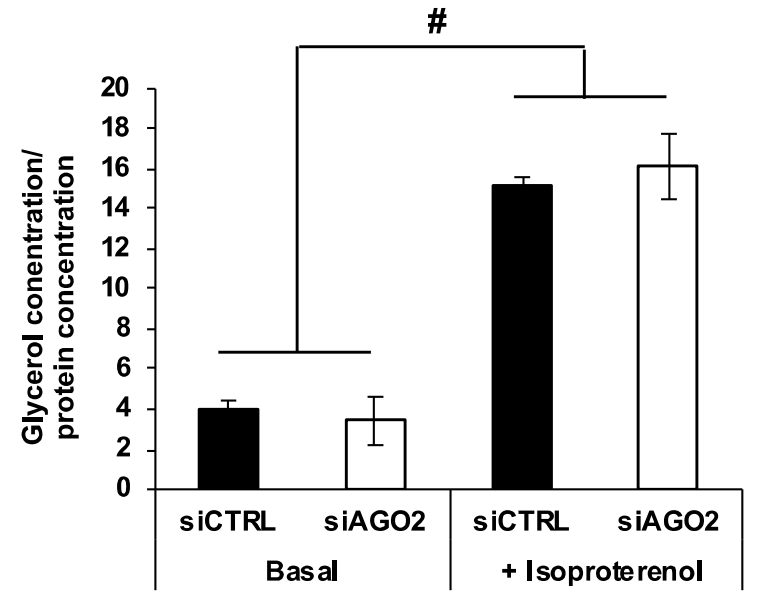

$\mathbf{F}$

Maximal Mitochondrial

Respiration

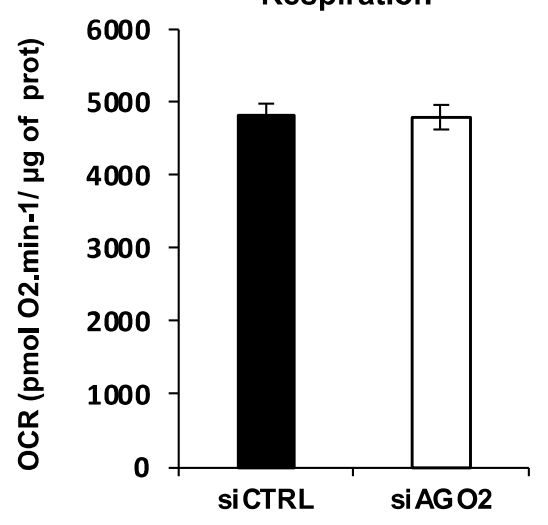

H

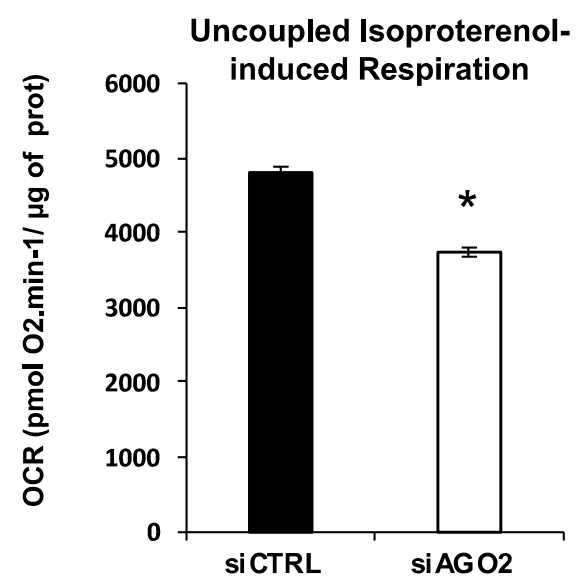

Figure 5 
Supplementary figures

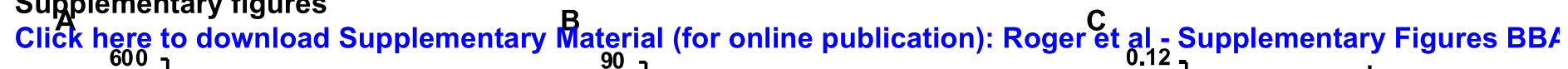
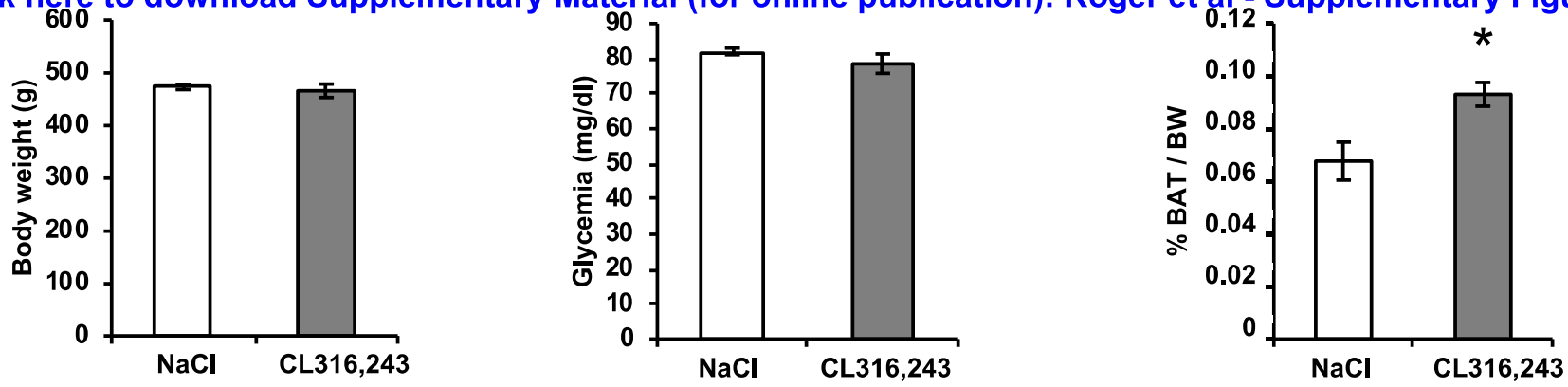

D
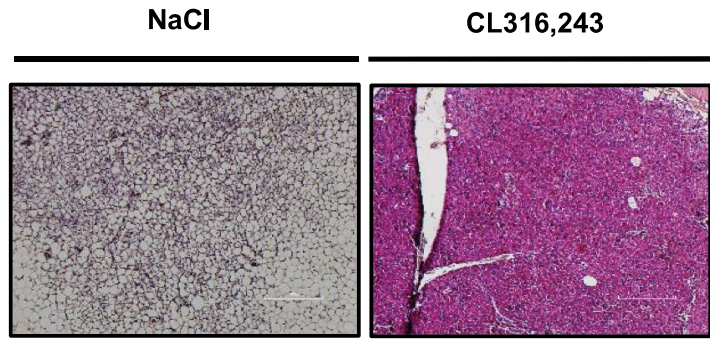

UCP1
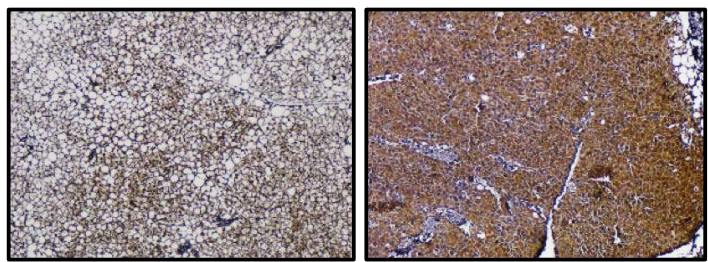

F

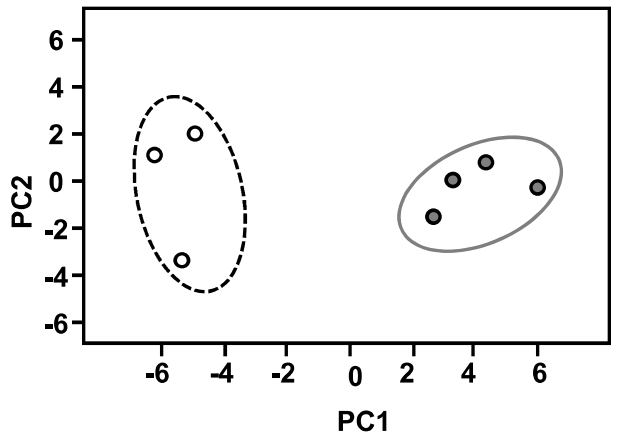

E

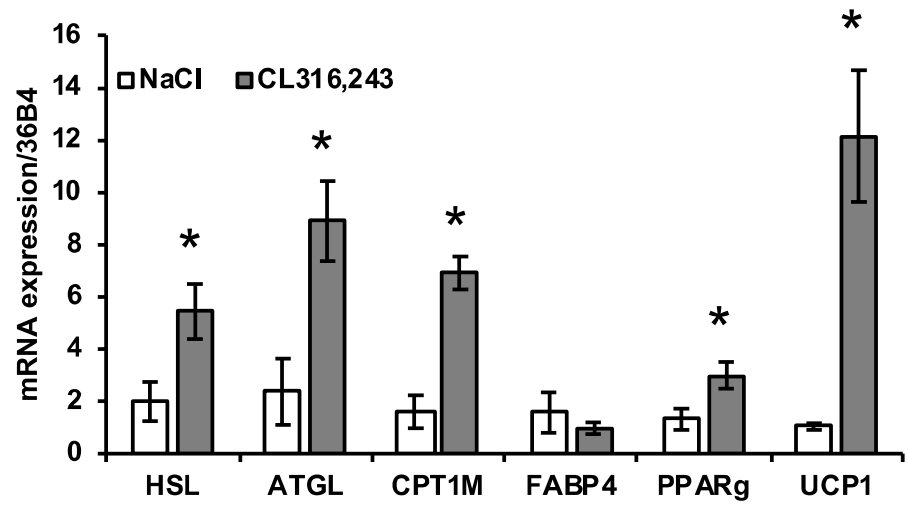

G

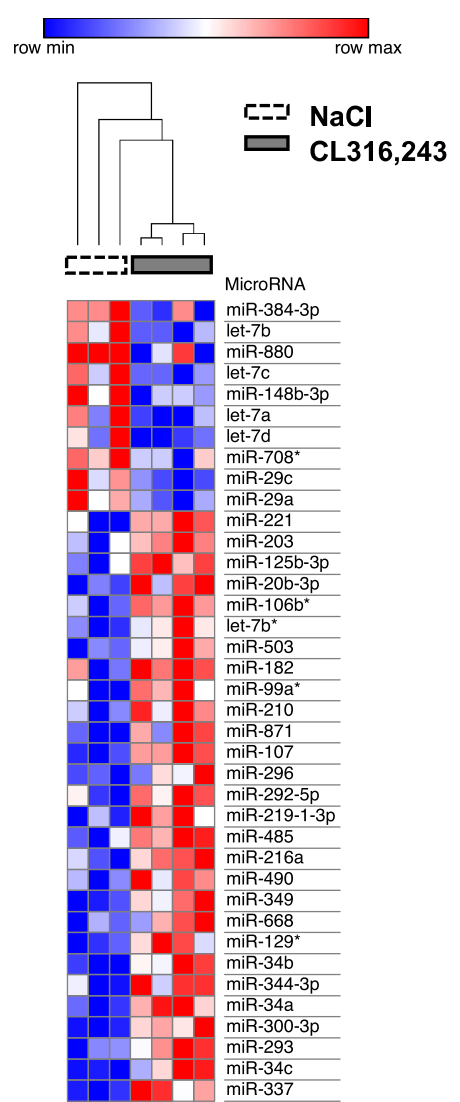

\section{Supplementary Figure 1}




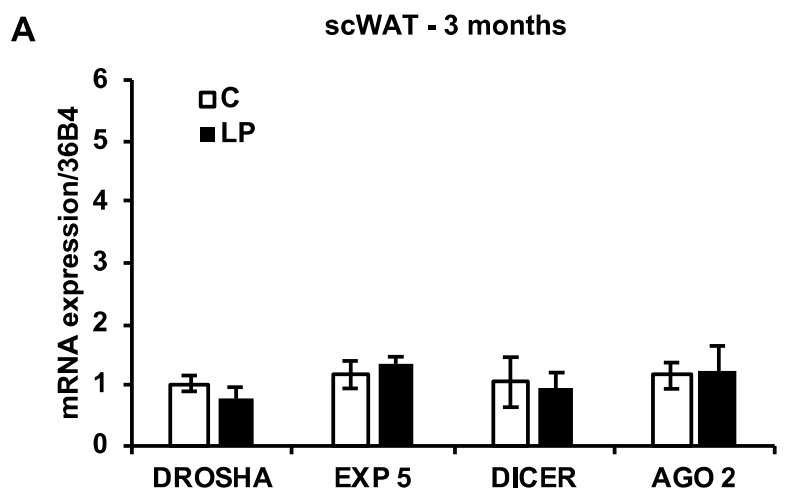

B

Brown-like scWAT - 3 months

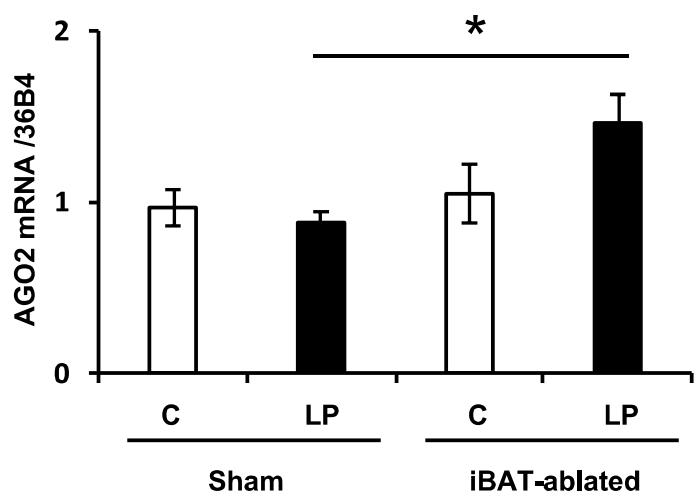

Supplementary Figure 2 
A

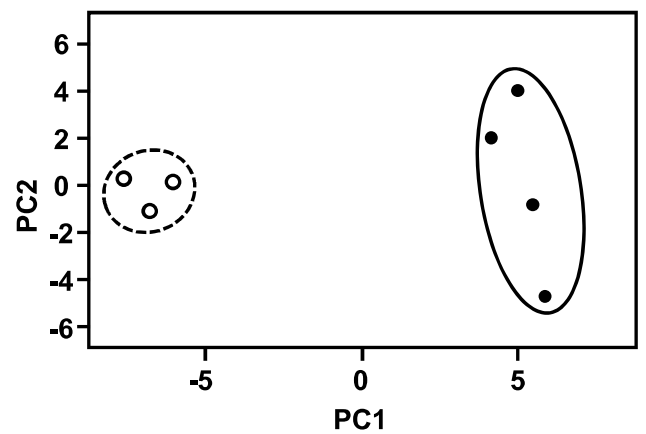

C

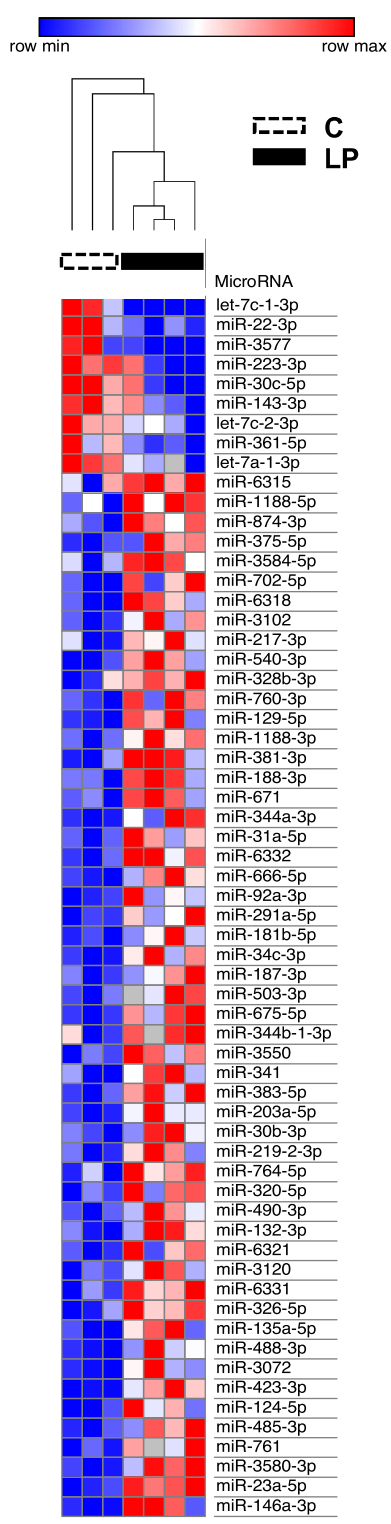

B

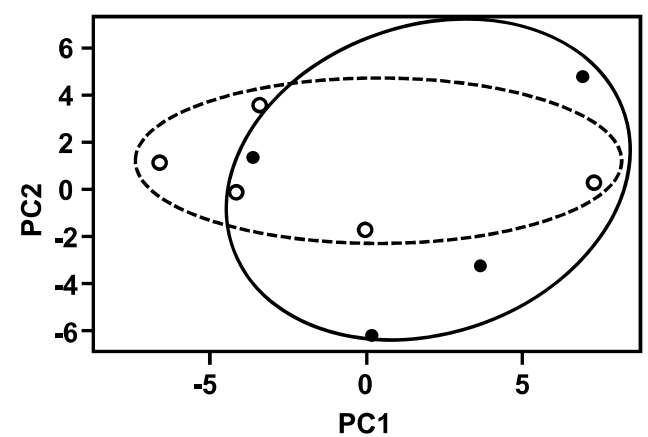

D
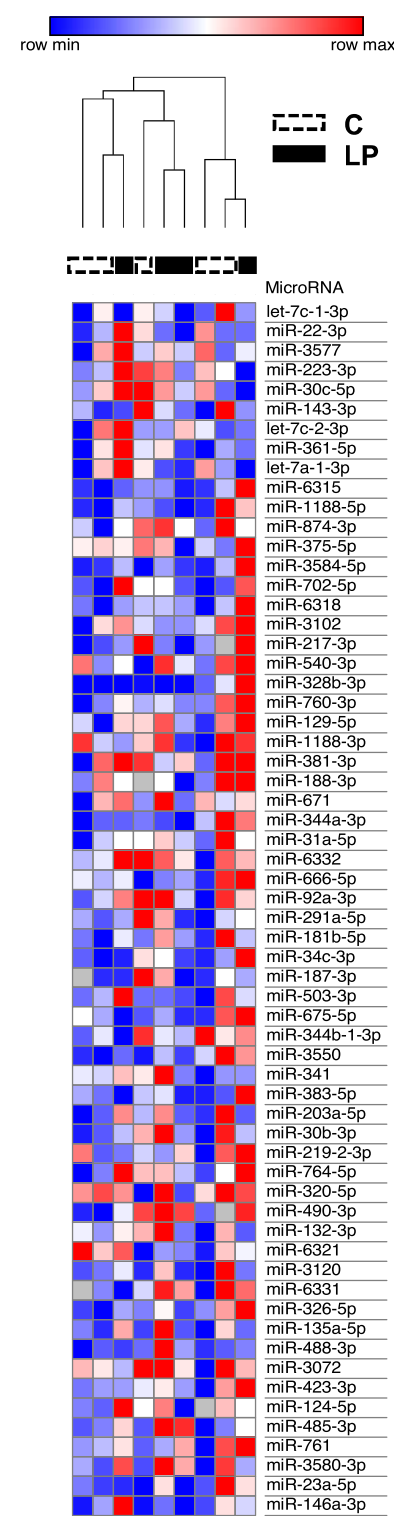
A
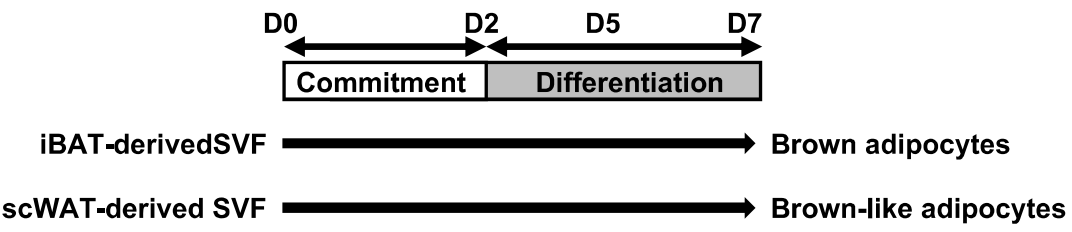

B

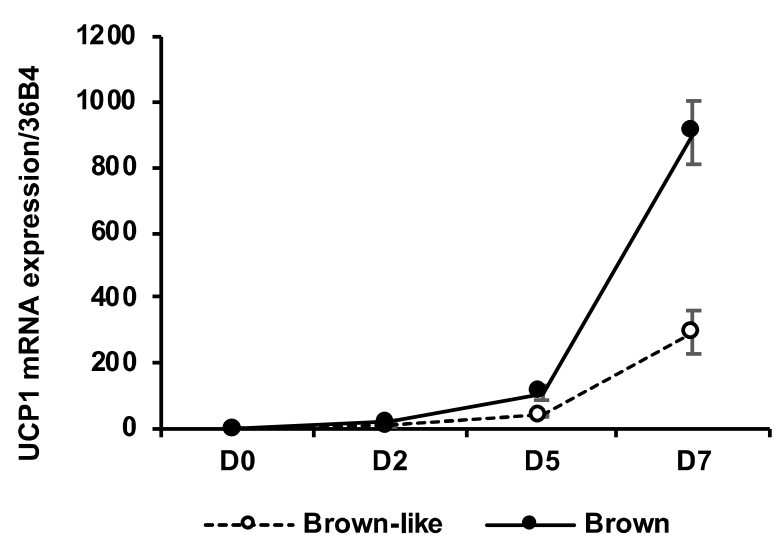

D

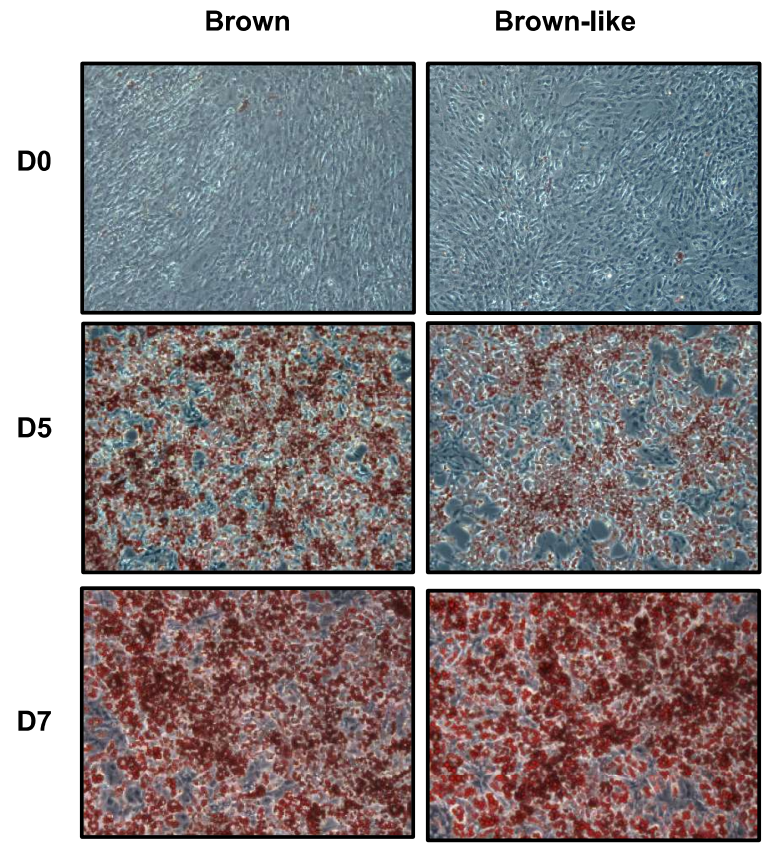

C

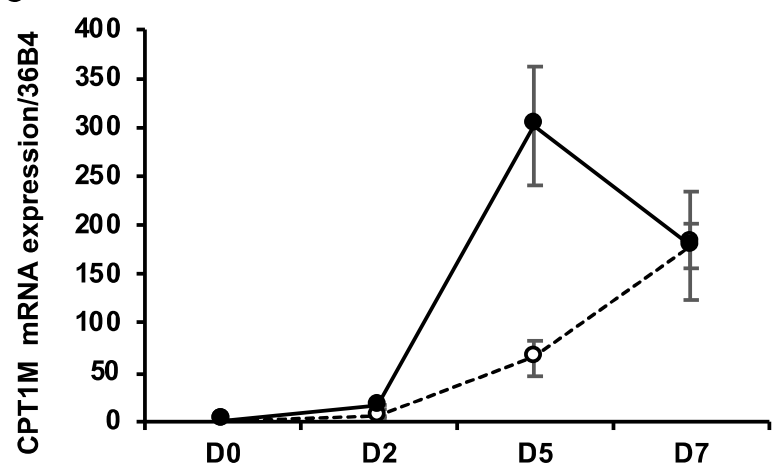

-.-.-.- Brown-like $\longrightarrow$ Brown

E

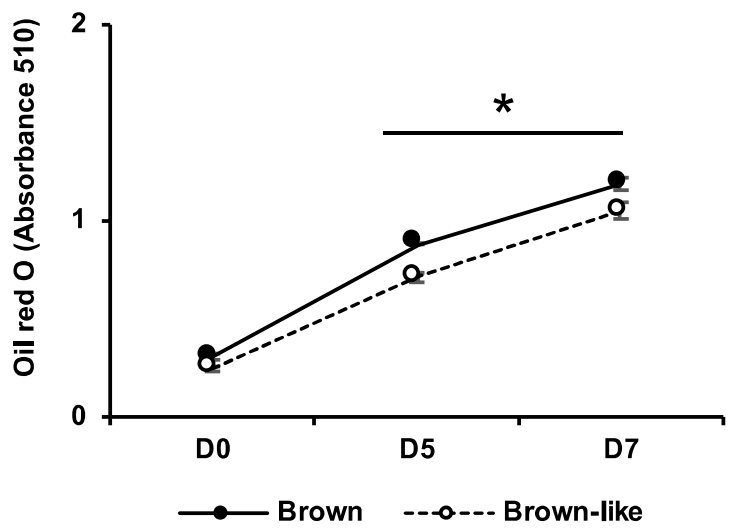

$\mathbf{F}$

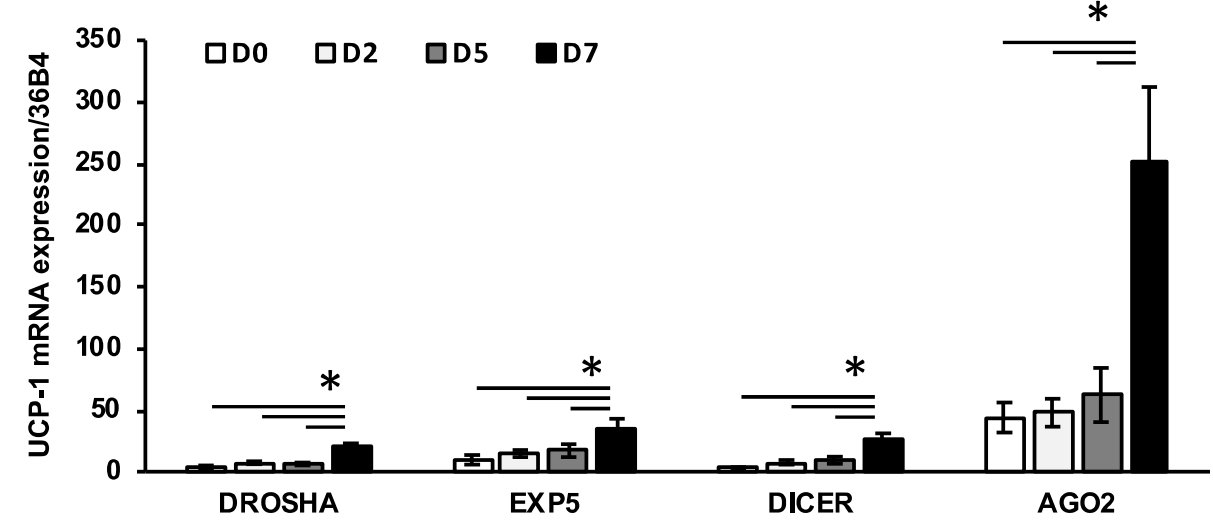

Supplementary Figure 4 
Supplementary Table 1

\begin{tabular}{|c|c|c|}
\hline Gene Name & Foward Sequence (5'->3') & Reverse Sequence (5'>>3') \\
\hline rUCP1 & TGCAATGACCATGTACACCA & CATAGGAGCCCAGCATAGGA \\
\hline rACC & TGCAGGTATCCCCACTCTTC & TTCTGATTCCCTTCCСТCCT \\
\hline rHSL & GTGGCACAGACCTCCAAATC & AGCCCAGCAGTAGGCAAAA \\
\hline rLPL & TATCCCAATGGAGGCACTTT & TGCTGGGGTTTTCTTCATTC \\
\hline rFABP4 & GTCGTCATCCGGTCAGAGAG & CCCCACCATCCAGGGTTATG \\
\hline rPPARg & AGGAGCAGAGCAAAGAGGTG & AGGCCAGCATGGTGTAGATG \\
\hline rPGC1a & TATGAAGCCAATGAGCACGA & GTGCATTCCTCAATTTCACC \\
\hline rATGL & GCCTACTGAACCAACCCAAC & CAGGTCTTTCGGTTCCACAC \\
\hline rCREB & GTAAATCGGGGTTGGCACTG & AGGAGTCTGTGGATAGTGTAACT \\
\hline rCPT1M & TGAGTGACTGGTGGGAAGAA & ACAGCAGTATGGCGTGGATG \\
\hline rCytC & AACCTCCATGGTCTGTTTGG & GTCTGCCCTTTCTCCCTTCT \\
\hline r36B4 & TCGGAGGAATCCGATGAGGA & TAAGCAGGCTGACTTGGTGT \\
\hline rAGO2 & AGTGTGGTTTGGCTTCCATC & TGGGAATCTGTCAGAGGTTTTT \\
\hline rDICER & AGACCCACGGCAGCATTCT & GCGACGCAAAGATGGTGTTAT \\
\hline rDROSHA & GGTGGCCGTTTACTTCAAAGG & GTCCATTGCTGCTCCCATTT \\
\hline rEXP5 & AGTTGGCCGAAAAAACACAAA & TCCACCGAAACTTGACAACGT \\
\hline
\end{tabular}


Supplementary Table 2

\begin{tabular}{|c|c|c|c|c|}
\hline MicroRNA (2-dCt) & C & CL & Fold (CL/C) & T.Test \\
\hline rno-miR-337 & 0.2 & 1.8 & 8.3 & 0.00 \\
\hline rno-miR-880 & 0.4 & 0.2 & 0.4 & 0.05 \\
\hline rno-miR-300-3p & 3.0 & 9.2 & 3.0 & 0.00 \\
\hline rno-miR-349 & 3.5 & 7.9 & 2.2 & 0.01 \\
\hline rno-miR-708* & 4.9 & 2.8 & 0.6 & 0.05 \\
\hline rno-miR-99a* & 6.6 & 11.8 & 1.8 & 0.03 \\
\hline rno-miR-216a & 6.7 & 14.1 & 2.1 & 0.01 \\
\hline rno-miR-485 & 9.5 & 19.1 & 2.0 & 0.01 \\
\hline rno-miR-384-3p & 13.5 & 5.2 & 0.4 & 0.03 \\
\hline rno-miR-292-5p & 15.2 & 30.6 & 2.0 & 0.03 \\
\hline rno-miR-20b-3p & 17.3 & 26.4 & 1.5 & 0.03 \\
\hline rno-miR-125b-3p & 19.6 & 28.6 & 1.5 & 0.01 \\
\hline rno-miR-503 & 21.5 & 37.7 & 1.8 & 0.02 \\
\hline rno-miR-490 & 33.4 & 72.3 & 2.2 & 0.02 \\
\hline rno-miR-34b & 35.3 & 95.9 & 2.7 & 0.01 \\
\hline rno-miR-219-1-3p & 38.6 & 77.7 & 2.0 & 0.01 \\
\hline rno-miR-293 & 50.3 & 171.6 & 3.4 & 0.01 \\
\hline rno-miR-129* & 59.9 & 135.5 & 2.3 & 0.01 \\
\hline rno-miR-106b* & 62.1 & 98.5 & 1.6 & 0.00 \\
\hline rno-miR-210 & 70.5 & 128.5 & 1.8 & 0.02 \\
\hline rno-miR-344-3p & 73.8 & 202.7 & 2.7 & 0.02 \\
\hline rno-miR-668 & 76.1 & 172.0 & 2.3 & 0.05 \\
\hline rno-miR-182 & 86.6 & 152.0 & 1.8 & 0.02 \\
\hline rno-miR-871 & 104.6 & 201.5 & 1.9 & 0.03 \\
\hline rno-miR-221 & 105.9 & 147.3 & 1.4 & 0.01 \\
\hline rno-miR-34c & 186.5 & 678.7 & 3.6 & 0.01 \\
\hline rno-miR-107 & 298.5 & 577.9 & 1.9 & 0.00 \\
\hline rno-let-7b* & 537.4 & 854.5 & 1.6 & 0.02 \\
\hline rno-miR-34a & 874.9 & 2583.1 & 3.0 & 0.00 \\
\hline rno-miR-29a & 1284.7 & 907.3 & 0.7 & 0.04 \\
\hline rno-miR-29c & 1307.0 & 821.6 & 0.6 & 0.03 \\
\hline rno-miR-203 & 1396.7 & 1964.0 & 1.4 & 0.03 \\
\hline rno-let-7d & 3152.0 & 1776.7 & 0.6 & 0.04 \\
\hline rno-let-7a & 4632.3 & 2515.8 & 0.5 & 0.05 \\
\hline rno-let-7b & 4741.3 & 1859.9 & 0.4 & 0.01 \\
\hline rno-let-7c & 8302.1 & 3780.1 & 0.5 & 0.02 \\
\hline rno-miR-296 & 10864.0 & 21361.2 & 2.0 & 0.05 \\
\hline rno-miR-148b-3p & 14647.8 & 6972.1 & 0.5 & 0.04 \\
\hline
\end{tabular}


Supplementary Table 3

\begin{tabular}{|c|c|c|c|c|}
\hline MicroRNA (2-dCt) & C & LP & Fold (LP/C) & T.TEST \\
\hline rno-miR-6321 & 0.1 & 0.2 & 4.3 & 0.05 \\
\hline rno-miR-146a-3p & 0.1 & 0.8 & 15.1 & 0.03 \\
\hline rno-miR-761 & 0.1 & 0.6 & 7.2 & 0.02 \\
\hline rno-miR-666-5p & 0.2 & 0.4 & 2.4 & 0.01 \\
\hline rno-miR-124-5p & 0.2 & 1.2 & 6.5 & 0.04 \\
\hline rno-miR-488-3p & 0.2 & 1.1 & 5.2 & 0.04 \\
\hline rno-miR-326-5p & 0.2 & 1.1 & 5.0 & 0.01 \\
\hline rno-miR-3580-3p & 0.2 & 2.1 & 9.9 & 0.01 \\
\hline rno-miR-675-5p & 0.2 & 0.7 & 2.9 & 0.01 \\
\hline rno-miR-23a-5p & 0.3 & 2.7 & 10.7 & 0.00 \\
\hline rno-miR-6331 & 0.3 & 1.3 & 5.0 & 0.01 \\
\hline rno-miR-3072 & 0.3 & 1.5 & 5.5 & 0.05 \\
\hline rno-miR-423-3p & 0.3 & 1.8 & 6.3 & 0.00 \\
\hline rno-miR-764-5p & 0.4 & 1.3 & 3.5 & 0.01 \\
\hline rno-let-7c-1-3p & 0.4 & 0.0 & 0.1 & 0.01 \\
\hline rno-miR-3120 & 0.4 & 1.8 & 4.4 & 0.04 \\
\hline rno-miR-219-2-3p & 0.4 & 1.4 & 3.4 & 0.04 \\
\hline rno-miR-383-5p & 0.4 & 1.3 & 3.2 & 0.01 \\
\hline rno-miR-344b-1-3p & 0.4 & 1.3 & 2.9 & 0.02 \\
\hline rno-miR-485-3p & 0.5 & 3.4 & 7.1 & 0.02 \\
\hline rno-miR-30b-3p & 0.5 & 1.7 & 3.4 & 0.05 \\
\hline rno-miR-320-5p & 0.5 & 1.9 & 3.6 & 0.03 \\
\hline rno-miR-6318 & 0.7 & 1.3 & 1.9 & 0.02 \\
\hline rno-miR-135a-5p & 0.8 & 3.8 & 5.1 & 0.04 \\
\hline rno-miR-490-3p & 0.8 & 3.1 & 3.8 & 0.03 \\
\hline rno-miR-3550 & 0.9 & 2.7 & 3.1 & 0.02 \\
\hline rno-miR-375-5p & 1.0 & 1.6 & 1.7 & 0.04 \\
\hline rno-miR-760-3p & 1.1 & 2.5 & 2.2 & 0.04 \\
\hline rno-miR-540-3p & 1.2 & 2.6 & 2.1 & 0.02 \\
\hline rno-miR-1188-5p & 1.4 & 2.3 & 1.6 & 0.02 \\
\hline rno-miR-381-3p & 1.4 & 3.2 & 2.3 & 0.02 \\
\hline rno-miR-874-3p & 1.5 & 2.5 & 1.7 & 0.01 \\
\hline rno-miR-31a-5p & 1.6 & 3.8 & 2.3 & 0.03 \\
\hline rno-miR-6332 & 1.8 & 4.3 & 2.4 & 0.00 \\
\hline rno-miR-187-3p & 2.2 & 5.8 & 2.6 & 0.05 \\
\hline rno-miR-291a-5p & 2.4 & 6.0 & 2.5 & 0.03 \\
\hline rno-miR-129-5p & 2.4 & 5.4 & 2.2 & 0.02 \\
\hline rno-miR-702-5p & 2.7 & 5.1 & 1.9 & 0.05 \\
\hline rno-miR-3584-5p & 2.8 & 4.9 & 1.8 & 0.02 \\
\hline rno-miR-1188-3p & 2.8 & 6.3 & 2.2 & 0.01 \\
\hline
\end{tabular}




\begin{tabular}{|l|c|c|c|c|} 
rno-miR-181b-5p & $\mathbf{3 . 1}$ & $\mathbf{7 . 8}$ & 2.5 & 0.05 \\
\hline rno-miR-6315 & $\mathbf{3 . 1}$ & $\mathbf{4 . 6}$ & 1.5 & 0.03 \\
\hline rno-miR-34c-3p & $\mathbf{3 . 1}$ & $\mathbf{8 . 1}$ & 2.6 & 0.01 \\
\hline rno-miR-188-3p & $\mathbf{3 . 2}$ & $\mathbf{7 . 3}$ & 2.3 & 0.02 \\
\hline rno-miR-503-3p & $\mathbf{3 . 3}$ & $\mathbf{9 . 1}$ & 2.8 & 0.02 \\
\hline rno-miR-671 & $\mathbf{3 . 4}$ & $\mathbf{7 . 7}$ & 2.3 & 0.02 \\
\hline rno-miR-361-5p & $\mathbf{3 . 4}$ & $\mathbf{1 . 6}$ & 0.5 & 0.02 \\
\hline rno-miR-217-3p & $\mathbf{3 . 9}$ & $\mathbf{8 . 2}$ & 2.1 & 0.04 \\
\hline rno-miR-22-3p & $\mathbf{3 . 9}$ & $\mathbf{0 . 7}$ & 0.2 & 0.02 \\
\hline rno-miR-92a-3p & $\mathbf{4 . 9}$ & $\mathbf{1 2 . 1}$ & 2.5 & 0.05 \\
\hline rno-let-7a-1-3p & $\mathbf{5 . 5}$ & $\mathbf{2 . 5}$ & 0.5 & 0.02 \\
\hline rno-miR-328b-3p & $\mathbf{5 . 7}$ & $\mathbf{1 2 . 2}$ & 2.1 & 0.03 \\
\hline rno-miR-344a-3p & $\mathbf{5 . 7}$ & $\mathbf{1 3 . 1}$ & 2.3 & 0.05 \\
\hline rno-let-7c-2-3p & $\mathbf{8 . 1}$ & $\mathbf{3 . 7}$ & 0.5 & 0.03 \\
\hline rno-miR-143-3p & $\mathbf{9 . 0}$ & $\mathbf{3 . 7}$ & 0.4 & 0.04 \\
\hline rno-miR-3102 & $\mathbf{1 0 . 0}$ & $\mathbf{2 1 . 0}$ & 2.1 & 0.03 \\
\hline rno-miR-132-3p & $\mathbf{2 1 . 9}$ & $\mathbf{8 6 . 1}$ & 3.9 & 0.03 \\
\hline rno-miR-341 & $\mathbf{2 3 . 5}$ & $\mathbf{7 5 . 1}$ & 3.2 & 0.03 \\
\hline rno-miR-3577 & $\mathbf{2 7 . 5}$ & $\mathbf{5 . 3}$ & 0.2 & 0.04 \\
\hline rno-miR-203a-5p & $\mathbf{4 3 . 4}$ & $\mathbf{1 4 5 . 5}$ & 3.4 & 0.02 \\
\hline rno-miR-223-3p & $\mathbf{8 8 . 0}$ & $\mathbf{3 3 . 3}$ & 0.4 & 0.04 \\
\hline rno-miR-30c-5p & $\mathbf{1 0 3 6 . 8}$ & $\mathbf{4 1 3 . 0}$ & 0.4 & 0.03 \\
\hline
\end{tabular}




\section{Supplementary figure 1: Expression analysis of significantly dysregulated miRNAs in} iBAT of rats chronically-injected with $\beta$-adrenergic receptor agonist. 3 month-old rats were daily intraperitoneally injected with $\mathrm{CL} 316,243(1 \mathrm{mg} / \mathrm{kg})$ or a saline solution $(\mathrm{NaCl} 0.9 \%$ $w / v)(n=4)$. A-C : (A) Body weight, (B) glycemia and (C) iBAT weight expressed as a percentage of BW. D : Representative immunohistochemistry of UCP1 with hematoxylin and eosin staining of iBAT. E: Relative mRNA expression levels of UCP1 and markers of adipocytes, lipogenesis and lipolysis from iBAT. Data are presented as mean $+/-$ SEM. * $p$ value $<0.05$. F. Global view of the significantly dysregulated miRNA expression by using principal component analysis (PCA). One minus Pearson correlation was used as a metric distance. Clustering of samples are indicated by ellipses. G: Hierarchical clustering heat map of significantly deregulated miRNAs with $p$-value $<0.05$ between between $\mathrm{NaCl}$ versus $\mathrm{CL}$ 316,243 injected rats. Columns represent samples and rows miRNAs. Color labelling for upand down-regulated miRNAs is indicated.

\section{Supplementary figure 2: Increased AGO2 mRNA expression in brown-like scWAT from} iBAT-ablated LP progeny: A: Relative mRNA expression level of miRNA machinery in scWAT of 3 month-old C and LP progenies $(n=4)$. B: Relative mRNA expression level of AGO2 in scWAT of 3 month-old sham or iBAT-ablated $C$ and LP progenies $(n=5)$. Data are presented as mean $+/$ - SEM. * $p$-value $<0.05$.

Supplementary figure 3: Expression analysis of significantly dysregulated miRNAs in iBAT of young and old LP progeny. A and B: Global view of the significantly dysregulated miRNA expression by using principal component analysis (PCA). Clustering of samples are indicated by ellipses. $\mathbf{C}$ and $\mathbf{D}$ : Hierarchical clustering heat map of significantly deregulated miRNAs with $p$-value $<0.05$ between $C$ and LP progenies at 3 months of age and their expression at 18 months. Columns represent samples and rows miRNAs. Color labelling for up- and down-regulated miRNAs is indicated.

Supplementary figure 4: Increased miRNA machinery during brown-like differentiation of scWAT-derived SVF progenitors. A: Scheme of the brown and brown-like adipocyte differentiation stages from SVF progenitors isolated respectively from iBAT and ScWAT during 7 days (D0 to D7) ( $n=6$ ). B-C: Relative mRNA expression levels of (B) UCP1 and (C) CPT1M in iBAT-derived or scWAT-derived SVF during brown adipocyte differentiation. Data are normalized to 36B4 mRNA and expressed in arbitrary units. D-E: (D) Representative pictures 
of oil red $\mathrm{O}$ staining in iBAT-derived or scWAT-derived SVF during brown adipocyte differentiation and $(F)$ quantification its absorbance at $510 \mathrm{~nm}$. F : Relative mRNA expression levels of miRNA machinery in scWAT-derived SVF during brown adipocyte differentiation. Data are presented as mean $+/$ - SEM. ${ }^{*} p$-value $<0.05$. 